OPEN ACCESS

Edited by: Jodhbir Mehta

Singapore National Eye

Center, Singapore

Reviewed by:

Sylvia Natalie Klodzinska,

University of Copenhagen, Denmark

Francesco Baino,

Politecnico di Torino, Italy

${ }^{*}$ Correspondence: Katelyn E. Swindle-Reilly

reilly.198@osu.edu

Specialty section: This article was submitted to Ophthalmology

a section of the journal

Frontiers in Medicine

Received: 01 October 2021 Accepted: 20 December 2021

Published: 28 January 2022

Citation:

Allyn MM, Luo RH, Hellwarth EB and Swindle-Reilly KE (2022)

Considerations for Polymers Used in Ocular Drug Delivery.

Front. Med. 8:787644. doi: 10.3389/fmed.2021.787644

\section{Considerations for Polymers Used in Ocular Drug Delivery}

\author{
Megan M. Allyn ${ }^{1}$, Richard H. Luo ${ }^{2}$, Elle B. Hellwarth ${ }^{2}$ and Katelyn E. Swindle-Reilly ${ }^{1,2,3 *}$ \\ ${ }^{1}$ William G. Lowrie Department of Chemical and Biomolecular Engineering, The Ohio State University, Columbus, $\mathrm{OH}$, \\ United States, ${ }^{2}$ Department of Biomedical Engineering, The Ohio State University, Columbus, OH, United States, \\ ${ }^{3}$ Department of Ophthalmology and Visual Sciences, The Ohio State University, Columbus, $\mathrm{OH}$, United States
}

Purpose: Age-related eye diseases are becoming more prevalent. A notable increase has been seen in the most common causes including glaucoma, age-related macular degeneration (AMD), and cataract. Current clinical treatments vary from tissue replacement with polymers to topical eye drops and intravitreal injections. Research and development efforts have increased using polymers for sustained release to the eye to overcome treatment challenges, showing promise in improving drug release and delivery, patient experience, and treatment compliance. Polymers provide unique properties that allow for specific engineered devices to provide improved treatment options. Recent work has shown the utilization of synthetic and biopolymer derived biomaterials in various forms, with this review containing a focus on polymers Food and Drug Administration (FDA) approved for ocular use.

Methods: This provides an overview of some prevalent synthetic polymers and biopolymers used in ocular delivery and their benefits, brief discussion of the various types and synthesis methods used, and administration techniques. Polymers approved by the FDA for different applications in the eye are listed and compared to new polymers being explored in the literature. This article summarizes research findings using polymers for ocular drug delivery from various stages: laboratory, preclinical studies, clinical trials, and currently approved. This review also focuses on some of the challenges to bringing these new innovations to the clinic, including limited selection of approved polymers.

Results: Polymers help improve drug delivery by increasing solubility, controlling pharmacokinetics, and extending release. Several polymer classes including synthetic, biopolymer, and combinations were discussed along with the benefits and challenges of each class. The ways both polymer synthesis and processing techniques can influence drug release in the eye were discussed.

Conclusion: The use of biomaterials, specifically polymers, is a well-studied field for drug delivery, and polymers have been used as implants in the eye for over 75 years. Promising new ocular drug delivery systems are emerging using polymers an innovative option for treating ocular diseases because of their tunable properties. This review touches on important considerations and challenges of using polymers for sustained ocular drug delivery with the goal translating research to the clinic.

Keywords: drug delivery, polymer, hydrogel, ophthalmic delivery, ocular implants, controlled release, ocular biomaterials 


\section{INTRODUCTION}

In 2020, the World Health Organization reported 196 million cases of age-related macular degeneration (AMD), 146 million cases of diabetic retinopathy (DR), 76 million cases of glaucoma, and 65 million cases of cataract globally (1). Nearly 44 million people in the United States (US) over the age of 40 are afflicted by some form of eye disease, with 2010 National Eye Institute statistics showing 24 million cataract cases, 11 million early and late stage AMD cases, 7 million DR cases, and 2 million glaucoma cases (2-4). While each disease has unique causes, symptoms, and treatments, all will result in complete vision loss if left untreated. Difficulties in ocular drug delivery stem from the complex anatomy of the eye, its compartmentalization, and its separation from the rest of the body.

Ocular anatomy is generally classified into two segments: the anterior segment comprised of the iris, cornea, lens, and surrounding aqueous humor; and the posterior segment including the vitreous humor, retina, macula, and optic nerve (5). Cataract and glaucoma impact the lens and fluid drainage pathways, respectively, in the anterior segment. The lens is responsible for accommodation, or fine focusing of light to produce vision. The proteins within the lens work to manage absorbed UV light to maintain the oxidative balance necessary for proper function. With age, the ability of the lens to mitigate oxidative damage and repair cellular damage diminishes, causing protein aggregation, lens opacities, and eventual vision loss due to cataract (6). Though not yet fully understood, it is believed that glaucoma develops when anterior fluid drainage systems based in the trabecular meshwork and uveoscleral outflow pathway become imbalanced (7). Impaired drainage causes an increase in intraocular pressure (IOP) that applies stress on anterior and posterior segments of the eye. Increased posterior IOP can subject the lamina cribrosa to conformational changes that inhibit axonal signal transportation to the optic nerve, resulting in retinal ganglion cell death and vision loss (7). This increased IOP has been theorized to also impact the cornea and corneal endothelium. In patients with angle-closure glaucoma, high IOP was found to cause up to an $11 \%$ decrease in endothelial cell density (8). Other common anterior segment disorders affecting the cornea include dry eye disease, corneal neovascularization, anterior uveitis, and keratitis.

Visual disorders affecting the posterior segment include retinal diseases such as AMD, non-proliferative and proliferative diabetic retinopathy (PDR), diabetic macular edema (DME), and posterior conjunctivitis. These present additional difficulties in treatment due to limited accessibility of disease sites and complexity of disease progression. In AMD, disease propagation occurs from an increased inflammatory environment caused by accumulation of reactive oxygen species (ROS) within the retina that leads to protein aggregation and drusen formation. This signals a local over-production of vascular endothelial growth factor (VEGF) that leads to abnormal blood vessel growth, permanently impacting the retinal pigment epithelium (RPE), leading to late stage "wet" $\operatorname{AMD}(9,10)$. Posterior segment diseases resulting from diabetes stem from increased levels of glucose in the bloodstream that cause pericyte apoptosis, outpouching of the capillaries, and the eventual development of microaneurysms. Hyperglycemic oxidative stress and chronic inflammation stimulate the expression of signaling cytokines that increase the permeability of the endothelium to VEGF, resulting in neovascularization, breakdown of the blood-retinal barrier (BRB), and neuronal degradation $(11,12)$.

Approved therapeutics for treatment of ocular diseases include steroids such as hydrocortisone, triamcinolone acetonide, fluocinolone, and dexamethasone; antibiotics such as fluoroquinolones, tetracyclines, and aminoglycosides; and biological pharmaceuticals such as anti-VEGFs. Experimental therapeutics currently being investigated include antioxidants such as glutathione and ascorbic acid, complement factor inhibitors such as avacincaptad pegol and APL-2, and novel therapeutic mechanisms such as mesenchymal stem cell extracellular vesicles, miotic based eye drops, viral vectors for gene therapy, and adenosine receptors (13-18).

Local delivery is often a necessity in the eye due to the BRB. However, direct administration through eye drops, subconjunctival injection, or intravitreal injection provide only short-term relief and require frequent administration, with outcomes heavily relying on patient compliance (19). Newly emerging ocular drug delivery technology has focused on the use of polymeric biomaterials to address the present obstacles within the field. Several current treatments rely on polymers to extend release duration in the eye, and extensive research is being conducted with current and investigational therapeutics to reduce application frequency.

In this review, a polymeric biomaterial is defined as large macromolecule composed of building blocks being applied in a biomedical application. These building blocks can be composed of synthetic monomers and/or natural components such as amino acids or sugars. These building blocks, in addition to polymer processing techniques, provide tunable chemical and physical characteristics to improve drug delivery and/or dosing of the therapeutic. Polymers are currently being used clinically to increase solubility of a drug in the target environment, control release rates of therapeutics, and improve drug retention within the eye $(5,20)$. The variety of polymers available to be used in drug delivery are vast but generally fall into two categories: synthetic polymers or biopolymers. The differences, benefits, and specific uses for both types are summarized below.

\section{SYNTHETIC POLYMERIC BIOMATERIALS}

Synthetic polymers are based on chemically derived monomers and provide a plethora of mechanical, chemical, and degradation options when utilized for ocular drug delivery applications. Notable synthetic polymers that are US Food and Drug Administration (FDA) approved for ocular applications and in clinical use include poly(ethylene glycol) (PEG), poly(vinyl alcohol) (PVA), poly(glycolic acid) (PGA), poly(lactic-co-glycolic acid) (PLGA), poly[2-(dimethylamino)ethyl methacrylate] (DMAEM), poly(caprolactone) (PCL), poly(acrylic acid) (PAA), and poly(amidoamine) (PAMAM), but many other polymers are available for experimental use or have been approved for 
use in different applications outside the eye. Monomers used to synthesize most of the synthetic polymers of interest are shown in Figure 1.

\section{Polyethylene Oxides}

PEG is a clear, colorless hydrophilic polymer based on ethylene oxide monomers that can increase the biocompatibility, solubility, and bioavailability of incorporated therapeutics. PEG is available in many forms (liquid, solid), molecular weights, configurations (e.g., linear vs. multi-armed), and activities (e.g., bioinert, tetrafunctional). It is generally regarded as safe (GRAS) by the FDA and is approved for many applications including ophthalmic use. Macugen $\AA$ is a PEGylated oligoribonucleotide, approved for use in 2004, that possesses a high binding affinity for VEGFs and is an injectable treatment for late stage AMD $(21,22)$. Shorter term implants such as Dextenza $\AA$, a PEGbased cylindrical implant, utilize the controlled release properties of PEG by slowing hydrolytic erosion to provide 1 month of dexamethasone release for both inflammation and pain management after surgery. The device is implanted through intracanalicular insertion, has been FDA approved since 2018 for its indicated use, and is currently in phase 3 clinical trials for treatment of allergic conjunctivits (23). Additional products from Ocular Therapeutix, such as their dexamethasone intracanalicular ophthalmic insert (OTX-DED) and tyrosine kinase inhibitor (OTX-TKI), use PEG. OTX-DED is a smaller dose, shorter duration therapeutic based on the same PEG technology as Dextenza ${ }^{\mathbb{R}}$ for delivering dexamethasone (24). The implant is an intracanalicular insert that is currently in phase 2 clinical trials for treatment of dry eye disease (24). OTX-TKI is an in situ forming injectable PEG hydrogel for sustained release of axitinib for treatment of wet AMD. The implant was developed to provide therapeutic for up to 12 months and is currently in phase 1 clinical trials (25). Topically applied ReSure $\AA$ sealant by Ocular Therapeutix is a in situ forming PEG hydrogel used to prevent wound leakage after cataract surgery (26). Experimental work done by Foroutan et al. (27) and Hussein et al. (28) confirms that incorporation of PEG units or PEGylation increases the bioavailability and corneal absorption of topically applied steroids by steric hinderance of hydrolytic enzymes and enhanced adherence to the subconjunctiva, reducing drug loss during tear clearance. In intravitreal injections, PEGylation has shown to improve the half-life of hydrophobic therapeutics in the vitreous, allowing for a longer, more effective targeting to the posterior of the eye (29). Further experimental work was completed by Lakhani et al. (30) and showed the incorporation of PEG in nanostructured lipid carriers helped to solubilize amphotericin $B$, an effective anti-mycotic compound for topical treatment of ocular fungal infections (30). PEG is currently used clinically, in clinical trials, and being investigated for both delivery systems and PEGylation of therapeutics.

\section{Polyvinyl Alcohols}

PVA is a water soluble, biodegradable polymer often used for solubilizing hydrophobic drugs, providing chemical resistivity and ease of processing (31). Variations in synthesis methods allow PVA to be obtained in a range of hydration states and molecular weights (31). PVA's polymer structure provides tunable permeability for controlled release applications. It is on the FDA GRAS list and is currently employed in several nondegradable implants used in the eye, including Vitrasert $\AA$, Retisert $\AA$, and Iluvien $\AA$. Vitrasert $\AA$ was the first FDA approved PVA and ethylene-vinyl acetate (EVA) copolymer implant for intravitreal treatment of cytomegalovirus retinitis, providing 6-8 months of therapeutic dosing through passive diffusive release from the implant (32). Retisert $\AA$ is a multi-layered implant that uses a permeable PVA outer layer to provide controlled release of fluocinolone acetonide for up to 2.5 years for treatment of noninfectious posterior uveitis $(32,33)$. Iluvien $₫$ was recently FDA approved for treatment of DME, and the delivery technology is in clinical trials for treatment of additional ocular conditions such as wet AMD. The PVA-based implant provides controlled release of fluocinolone acetonide to the vitreous chamber for up to 36 months (34-36). While similar in composition and eluted therapeutic to Retisert $\AA$, implantation of Iluvien $\AA$ can be completed in out-patient facilities due to its smaller size, reducing surgical risks (37). Yutiq $\AA$ is another recently approved polyimide/PVA implant for controlled release of fluocinolone acetonide, improving not only on the administration method of both Retisert $(\mathrm{R}$ and Iluvien $\AA$, but also on the ability to treat uveitis (38). PVA is also being evaluated for topical ocular drug delivery through wafers (39).

\section{Polyesters}

PGA, PLA, and PLGA are the most common synthetic polymers in drug delivery vehicles used to treat ocular diseases and are FDA approved for ocular use. These hydrophobic polyesters provide tunable in vivo biodegradation based on the monomer ratio incorporated in the polymer, and have seen usage as drug carriers for small molecules, proteins, and genes (40). PLA and PGA are composed of naturally sourced lactic acid and glycolic acid monomers; both are synthesized through ring-opening polymerization (41). Due to its susceptibility to hydrolysis, PGA has a faster degradation rate compared to PLA, which has an in vivo biodegradation rate of up to 2 years, but biodegradation of both polymers produces non-toxic byproducts (42). PLA has high thermal stability and can be formed by many methods, i.e., injection molding and extrusion (42). PGA is brittle and insoluble in common organic solvents, thus limiting its processing as a standalone polymer; however, it is often used in conjunction with other polymers. Utilization of PLA's slow biodegradation rate can be seen in Brimo DDS $\AA$, an intravitreal implant containing PLA for slow release of brimonidine for treatment of geographic atrophy which has completed phase 2 clinical trials (43).

PGA and PLA are often co-polymerized to produce PLGA, which offers tunable monomer ratios and end groups that alter biodegradation profiles. Implementation of PLGA for ocular drug delivery vehicles is aimed at controlling the release of therapeutic through tunable polymer properties and improving biocompatibility and bioavailability. Altering the ratios of PGA and PLA also allows for optimization of degradation time, degrees of crystallinity, and hydrophobicity (44). Incorporation of a hydrophobic polymer can allow for selective permeation across mucus membranes if applied 


\section{Repeating Units for SYNTHETIC Polymers in Ocular Drug Delivery}
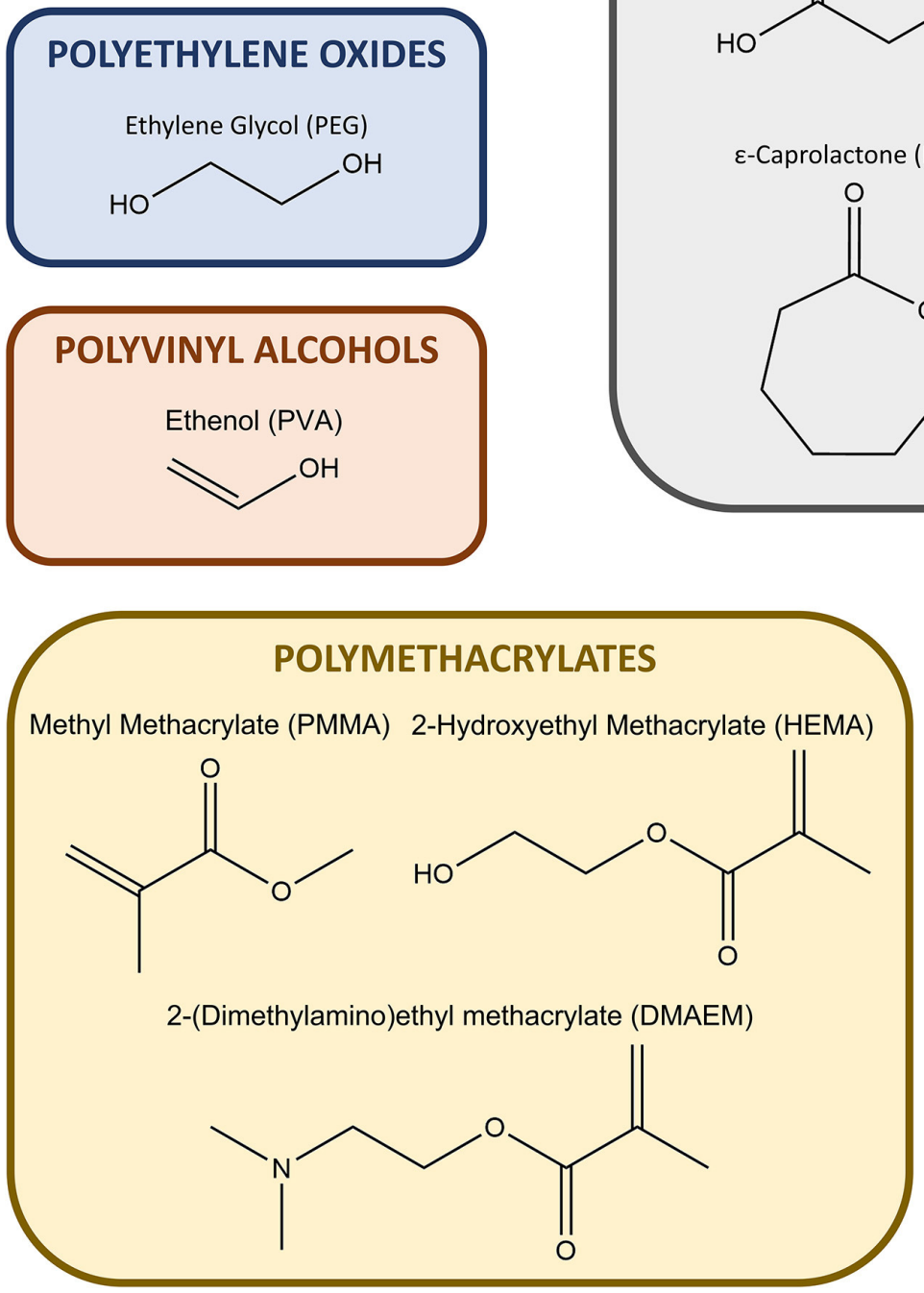

\section{POLYESTERS}

Glycolic Acid (PGA, PLGA) Lactic Acid (PLA, PLGA)<smiles>O=C(O)CO</smiles><smiles>CC(O)C(=O)O</smiles>

$\varepsilon$-Caprolactone (PCL)

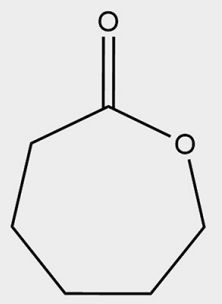

Ortho Ester (POE)

$\mathrm{R}^{2}$

$\mathrm{R}^{2}$

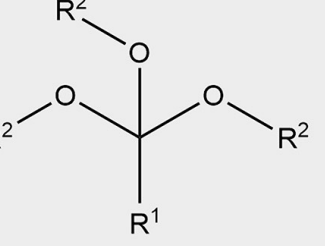

\section{POLYOLEFINS}

Acrylic Acid (PAA)

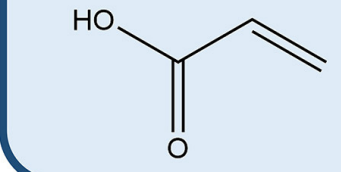

\section{DENDRIMERS}

Ethylenediamine (PAMAM)*

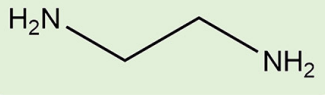

*Ethylenediamine is just one example of the most commonly used primary amines for PAMAM synthesis (along with ammonia, and cystamine).

FIGURE 1 | Schematic of monomers that form the most common synthetic polymers used in ocular drug delivery.

topically, or, if administered intravitreally, can work to minimize diffusion of therapeutic away from the target region and slow release. These degradation characteristics make PLGA one of the most common biomaterials found in approved polymeric ocular drug delivery vehicles. However, there have been challenges with some PLGA-based systems due to acidic degradation byproducts $(44,45)$. Ozurdex $\mathbb{R}$ is an FDA approved PLGA-based intravitreal implant used for extended release of dexamethasone in treatment of retinal vein occlusion, noninfectious posterior uveitis, and DME. The implant is coextruded with dexamethasone to provide controlled release for
4-6 months and degrades entirely in vivo $(46,47)$. PLGA-based implant Durysta $\AA$ has been recently approved for controlling IOP in patients with open angle glaucoma. A schematic of the implant applicator and location shown in Figure 2. The implant provides controlled release of the prostaglandin analog bimatoprost, lowering IOP for 4-6 months (48). Beyond these biodegradable implants, PLGA is currently being investigated for use in hydrogel, microparticle, and nanoparticle delivery systems. There have been several promising preclinical studies evaluating an intravitreal biodegradable system with PLGA microspheres embedded in a hydrogel for delivery of biologics for treatment 


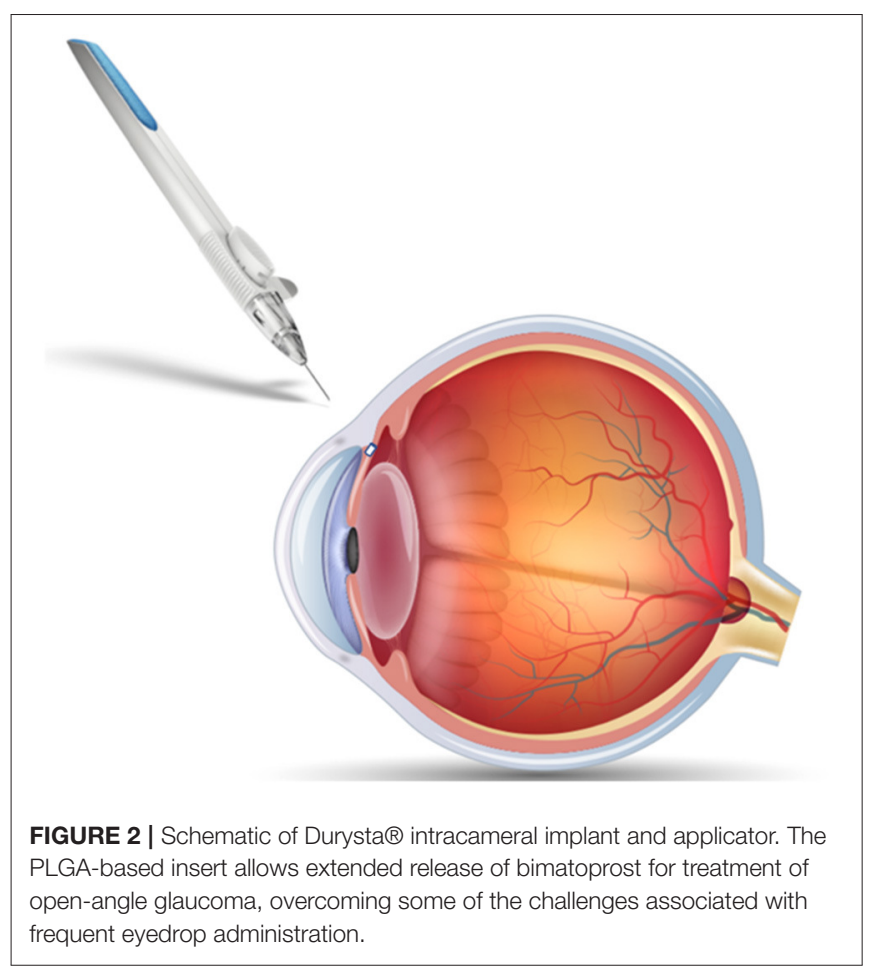

of wet AMD (49-52). PLGA is a popular choice for ocular drug delivery due to its clinical acceptance and tunable properties, but is limited by a 6 month release duration.

PCL is composed of $\varepsilon$-caprolactone monomers and is formed through induced ring opening polymerization. It is a hydrophobic, semicrystalline polymer with a slow biodegradation rate, taking months to years depending on polymer molecular weight and implant size and location (53). PCL is a common choice for experimental drug delivery vehicles due to its low cost, ease of modification and copolymerization, and processability. While it has been FDA approved for other indications such as in sutures, it has not yet been approved for use in the eye (54). PCL's crystalline properties make it an excellent choice for thin films and cell delivery due to its ability to maintain structural integrity through late stages of degradation. Experimental work done by Shuamo et al. (55) and Samy (56) present PCL thin films capable of extended drug release with limited intraocular inflammation. Additionally, PCL has shown promise as an intraocular drug delivery vehicle, with recent experimental work focusing on embedding nanoparticles within contact lenses, injectable in situ forming hydrogels, nanoparticle emulsions and suspensions, microparticles, and capsules for treatment of several diseases including glaucoma and wet AMD (57-62).

Poly(ortho ester) (POE) is another notable polyester-based synthetic polymer that has seen use in ocular drug delivery vehicles. While POE has been FDA approved for drug delivery in other applications, it has not yet been approved for ocular drug delivery but shows potential as a promising candidate that relies on surface erosion for therapeutic release. A thermosetting
PEG-Polyacetal-POE hydrogel has been developed and patented for drug delivery (63). The use of POE as a therapeutic delivery system appears to hold significant untapped potential.

\section{Polymethacrylates}

Poly(methyl methacrylate) (PMMA) and other methacrylatebased polymer derivatives are acrylic, biocompatible thermoplastics that possess good optical clarity when processed, high mechanical strength, water transmissibility and thermal stability $(64,65)$. They are FDA approved for intraocular use, and were first used in ocular applications in contact lenses in 1936 (66). Methacrylate based polymeric biomaterials have expanded to include uses in nanoparticle and micelle delivery, ocular hydrogels for topical administration and intravitreal injection, and ocular implants. Notable methacrylate derivatives include poly(2-hydroxylethylmethacrylate) (HEMA) and poly(2-(dimethylamino)ethyl methacrylate) (DMAEM). Titanium-based intravitreal implant I-vation $\AA$ utilized PMMA as a non-biodegradable polymer coating for sustained release of triamcinolone acetonide for patients with DME (32). The implant was successful through phase I clinical trials but was suspended in phase IIb (67). Drug eluting HEMA-based contact lenses are a growing focus in ocular drug delivery because of the large population of contact wearers. In particular, experimental work with Acuvue $\AA$ HEMA-based soft contacts has shown their potential as drug delivery vehicles, capable of extended release of Ofloxacin after incorporation of a vitamin E release barrier (68). Work by Pereira-da-Mota et al. (69) utilizes HEMA and other methacrylates for experimental atorvastatin-eluting lenses for topical treatment of diabetes-related ocular diseases. The formed contacts were designed to contain molecules similar to natural cholesterol regulator 3-methylglutaryl-CoA to improve incorporation of lipophilic drugs into the polymer matrix. Experimental work with methacrylate-based polymers includes investigations into HEMA-based lenses for elution of olopatadine for allergic conjunctivitis, HEMA contact lenses with temperature triggered release for treatment of glaucoma, and DMAEM nanogel-based drug carriers to increase mucoadhesion in topically administered delivery vehicles (70-72).

\section{Polyolefins}

Poly(acrylic acid) (PAA), also known commercially as Carbopol $\AA$, is a synthetic polymer composed of acrylic acid monomers with high water solubility and viscosity enhancing properties (73). It is biodegradable, but the resultant acrylic acid byproducts can cause inflammation (74). PAA displays good mucoadhesive properties due to its charged state at physiological conditions and has found use in several experimental hydrogel applications for anterior ocular delivery including copolymerization with PNIPAAm for generation of thermally sensitive in situ forming hydrogels for controlled release of epinephrine for glaucoma $(75,76)$. PAA is FDA approved for many topical applications including ocular administration and is commercially available in several eye drops, including the drug eluting ophthalmic emulsion Restasis $(\mathrm{R})$. Restasis $(\mathrm{C}$ is a carbomer copolymer type A-based 
emulsion for topical administration of cyclosporine for treatment of dry eye disease (77).

\section{Dendrimers}

Dendrimers are long branching chain polymers that have distinct physical and chemical properties depending on chain characteristics and branch functionalization. Dendrimers have found application in ocular drug delivery due to their biocompatibility, water solubility, drug entrapment capabilities, and the reactivity of terminal functional groups at the end of each branch (78). The variety of dendrimers, their ability to hold several surface charge groups, and the ease of drug entrapment make them a superior polymer system for drug delivery (79). Poly(amidoamine) (PAMAM) is a dendrimer with FDA approval for certain uses that has seen use as a tool for ocular drug delivery, but is not on the GRAS list due to toxicity concerns (80). Experimental work completed by Yavuz et al. (81). evaluated PAMAM conjugation with dexamethasone for posterior eye sustained drug release for AMD and DR while Iezzi et al. (82). investigated PAMAM conjugation with fluocinolone acetonide for treatment of retinal inflammation in AMD and retinitis pigmentosa. Both works showed successful conjugation of the therapeutic into the dendrimer and were administered via intravitreal injection into rats. Topical administration of PAMAM hydrogels has also been reported, with one publication presenting a crosslinked PAMAM-PEG hydrogel for controlled delivery of the anti-glaucoma drug brimonidine tartrate (83). The current regulatory status, advantages, and disadvantages of common synthetic polymers are listed in Table $\mathbf{1}$.

\section{BIOPOLYMERS OR BIOLOGICALLY DERIVED POLYMERIC BIOMATERIALS}

Biopolymers have become more widely used in polymeric applications as technology for production has improved and understanding of material properties increases. They are based on naturally derived monomers or building blocks (animal, plant, fungi, bacteria) and generally possess high biocompatibility, fast degradation in aqueous environments, and a broad range of viscoelastic properties with the potential to produce biomaterials for use in ocular drug delivery (84). Common biological polymers in use for ocular biomaterials and drug delivery systems include cellulose, chitosan, hyaluronic acid (HA), collagen, carboxymethyl cellulose (CMC), gelatin, dextran, guar gum, pullulan, and polydopamine. The monomers and repeating units that produce those biological polymers are displayed in Figure 3.

\section{Polysaccharide Biopolymers}

Cellulose is considered the most common biopolymer and is derived from plant cell walls. It contains a large number of hydroxyl units and is thus very hydrophilic. It is biocompatible, biodegradable through enzymatic reactions and hydrolysis, easily conjugated and reacted, FDA approved for ocular use, and relatively inexpensive. For ocular drug delivery, carboxymethylcellulose (CMC), an ether derivative of cellulose, is the most prominent version of the polysaccharide as the addition of carboxy groups to the biopolymer chains increases water solubility (84). Due to its biocompatibility and hydrophilicity, CMC is often found in topically administered eye drops

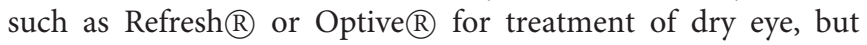
many more brands and formulations are available (85). The linear nature of CMC provides an excellent framework for experimental biopolymer-based hydrogels and thin films for extended topical drug release and in situ forming gels for intravitreal injection. Recent work by Deng et al. (86) synthesized in situ forming $\mathrm{CMC} / \mathrm{HA}$ hydrogels capable of releasing bovine serum albumin for up to 30 days. CMC based micro- and nanocarriers have also been produced for anterior and posterior ocular drug delivery. Experimental work from Yuan et al. (87) produced and characterized CMC-based nanowafers for extended anterior drug delivery of axitinib. The topically applied clear nanowafers contain nanoreservoirs of therapeutic for extended drug release and increased bioavailability compared to traditional eye drop delivery. Additionally, experimental CMC nanowafers for extended release of dexamethasone have been shown to effectively treat dry eye disease (88). The nanowafers contained a $500 \mathrm{~nm}$ array of drug reservoirs and showed successful drug release for $24 \mathrm{~h}$. Another notable cellulose derivative, hydroxypropyl methylcellulose (HPMC), is commonly used in ocular drug delivery due to its viscosity enhancing properties and biocompatibility (89).

Chitosan is a polysaccharide comprised of glucosamine and $\mathrm{N}$-acetyl-glucosamine monomers that possesses a strong positive charge due to primary amine groups along the backbone (90). The highly cationic nature of the polymer provides mucoadhesive benefits that have been employed for use in eye drops, to improve therapeutic bioavailability, and extended release gels for subconjunctival injection $(91,92)$. The amphiphilic nature of chitosan allows for improved solubility of hydrophobic drugs and increased penetration through the corneal membrane when compared to non-conjugated drug (93). Chitosan has limited FDA approval and is not currently approved for ocular applications; however, there are several publications demonstrating in vitro and in vivo efficacy (94). Technologies such as chitosan liposomes and micelles provide a high drug payload with longer drug release period that can be easily administered through intravitreal injection. Because of its cationic nature, chitosan is often employed as a polymer coating for less biocompatible anionic polymers, used in layer by layer assembly of core shell biomaterials, and used for delivery of anionic therapeutics and genetic material $(60,61,95)$. Chitosan-based hydrogels have recently been investigated to increase bioavailability of the topically administered antibiotic, levofloxacin (96). Thermosensitive hexanoyl glycol chitosan hydrogels were shown to possess low ocular irritation and 1.92fold greater bioavailability in the aqueous humor of rabbits when compared to traditional antibiotic suspension.

Like chitosan, hyaluronic acid (HA) is a hydrophilic polysaccharide made up of D-glucuronic and $\mathrm{N}$-acetylglucosamine monomers. HA is endogenously found in many ocular tissues including the cornea, aqueous humor, vitreous humor, and retina, and fulfills a variety of important roles in the eye. HA's structure allows for high water content and potential swelling in aqueous environments and fast degradation 
TABLE 1 | Summary of synthetic polymers, biomaterial uses, regulatory status, benefits, and disadvantages.

\begin{tabular}{|c|c|c|c|c|c|}
\hline Polymer name & $\begin{array}{l}\text { Experimental/Clinical/FDA } \\
\text { approved biomaterial } \\
\text { forms }\end{array}$ & GRAS & $\begin{array}{l}\text { FDA approved } \\
\text { indications }\end{array}$ & Approved for use in eye & Pros/Cons \\
\hline $\begin{array}{l}\text { Poly(ethylene glycol) } \\
\text { (PEG) }\end{array}$ & $\begin{array}{l}\text { Implants, hydrogels, } \\
\text { nanoparticles }\end{array}$ & Yes & $\begin{array}{l}\text { Yes: injectables, topicals, } \\
\text { rectal and nasal }\end{array}$ & Yes & $\begin{array}{l}\text { Pros: water soluble, } \\
\text { biocompatible } \\
\text { Cons: fast degradation } \\
\text { compared to other synthetic } \\
\text { polymers }\end{array}$ \\
\hline $\begin{array}{l}\text { Poly(vinyl alcohol) } \\
\text { (PVA) }\end{array}$ & $\begin{array}{l}\text { Implants, hydrogels, } \\
\text { nanoparticles }\end{array}$ & Yes & $\begin{array}{l}\text { Yes: coatings, food } \\
\text { additives, food packaging }\end{array}$ & Yes & $\begin{array}{l}\text { Pros: slow degradation rate } \\
\text { Cons: synthesized with } \\
\text { aggressive solvents }\end{array}$ \\
\hline $\begin{array}{l}\text { Poly(glycolic acid) } \\
\text { (PGA) }\end{array}$ & Implants & Yes & $\begin{array}{l}\text { Yes: absorbable sutures, } \\
\text { medical devices }\end{array}$ & Yes & $\begin{array}{l}\text { Pros: fast degradation rate } \\
\text { Cons: weak mechanical } \\
\text { properties, brittle }\end{array}$ \\
\hline $\begin{array}{l}\text { Poly(glycolic acid - } \\
\text { co - lactic acid) } \\
\text { (PLGA) }\end{array}$ & All types & Yes & $\begin{array}{l}\text { Yes: implants, drug } \\
\text { delivery, medical devices }\end{array}$ & Yes & $\begin{array}{l}\text { Pros: tunable degradation rate, } \\
\text { water soluble, most common } \\
\text { polymer used in ocular drug } \\
\text { delivery } \\
\text { Cons: acidic degradation } \\
\text { byproducts }\end{array}$ \\
\hline Poly(lactic acid) (PLA) & All types & Yes & $\begin{array}{l}\text { Yes: absorbable sutures, } \\
\text { medical devices, food } \\
\text { packaging }\end{array}$ & Yes & $\begin{array}{l}\text { Pros: Synthesized from natural } \\
\text { sources, easily processed } \\
\text { Cons: slow degradation rate }\end{array}$ \\
\hline $\begin{array}{l}\text { Poly(caprolactone) } \\
\text { (PCL) }\end{array}$ & $\begin{array}{l}\text { Hydrogels, films, } \\
\text { nanoparticles }\end{array}$ & No & $\begin{array}{l}\text { Yes: implants, delivery } \\
\text { devices }\end{array}$ & No & $\begin{array}{l}\text { Pros: easily modified, } \\
\text { inexpensive } \\
\text { Cons: not FDA approved for } \\
\text { ocular applications }\end{array}$ \\
\hline $\begin{array}{l}\text { Poly(orthoester) } \\
\text { (POE) }\end{array}$ & Nanoparticles & No & Yes: drug delivery & No & $\begin{array}{l}\text { Pros: degrades via surface } \\
\text { erosion } \\
\text { Con: not heavily investigated for } \\
\text { drug delivery uses }\end{array}$ \\
\hline $\begin{array}{l}\text { Poly(methacrylates) } \\
\text { and derivatives } \\
\text { (PMMA) }\end{array}$ & Hydrogels, contact lenses & Yes (mostly) & $\begin{array}{l}\text { Yes: coatings, ocular } \\
\text { lens, dental fillers, bone } \\
\text { cement }\end{array}$ & Yes & $\begin{array}{l}\text { Pros: well established ocular } \\
\text { polymer, inexpensive } \\
\text { Cons: non-biodegradable }\end{array}$ \\
\hline Poly(acrylic acid) PAA & Hydrogels, eye drops, & No & Yes: topicals, & Yes & $\begin{array}{l}\text { Pros: highly water soluble, } \\
\text { mucoadhesive } \\
\text { Cons: biodegradation into acidic } \\
\text { byproducts }\end{array}$ \\
\hline $\begin{array}{l}\text { Poly(amidoamine) } \\
\text { (PAMAM) }\end{array}$ & Nanoparticles, hydrogels & No & $\begin{array}{l}\text { Yes: topicals, drug } \\
\text { delivery }\end{array}$ & No & $\begin{array}{l}\text { Pros: easily functionalized, } \\
\text { contains many reactive groups } \\
\text { Cons: not FDA approved for } \\
\text { ocular uses }\end{array}$ \\
\hline
\end{tabular}

via enzymatic pathways (97, 98). HA's biocompatibility, high degree of hydration, tunable water content, and viscoelastic properties have made it a popular choice for certain types of ocular drug delivery systems such as polymer gels. It has also been used as a biocompatible coating for delivery devices, and as an integral part of retinal cell based therapies (99). Work by Liu et al. (100) showed that delivery of retinal progenitor cells using a HA-based hydrogel was able to correctly transplant the cells into the sub-retinal area without disruption of function and that upon complete degradation of HA, the cells expressed mature photoreceptor markers (100). HA has also recently been applied as a self-sealing inner needle coating for intravitreal injection to minimize extraocular regurgitation of drugs (101). The most common application of HA has been as a lubricating agent in eyedrops for dry eye, with HA eyedrops serving as an artificial tear layer in products such as Optive Fusion, Vismed Multi, DROPSTAR $\AA$, Hyalistil $\AA$, and Neop (85, 102). Other applications include the Solaraze ${ }^{\mathrm{TM}}$ gel, which uses HA gel to form a depot for controlled release of diclofenac for treatment of ocular inflammation and pain $(102,103)$. Future research is likely to explore this further, as HA presents an easily prepared and biodegradable polymer with significant potential for the formation of degradable reservoirs for controlled drug release in addition to hydration and healing properties.

Dextran is a polysaccharide biopolymer composed of $\mathrm{D}$ glucose units and is synthesized by lactic acid bacteria. It is biocompatible, biodegradable, hydrophilic, and able to form hydrogels (104). Dextran is an FDA approved biopolymer found in ophthalmic eye drop solutions such as Tears Natural Forte $\AA$ and Tears Natural II $\cap$ for treatment of dry eye 

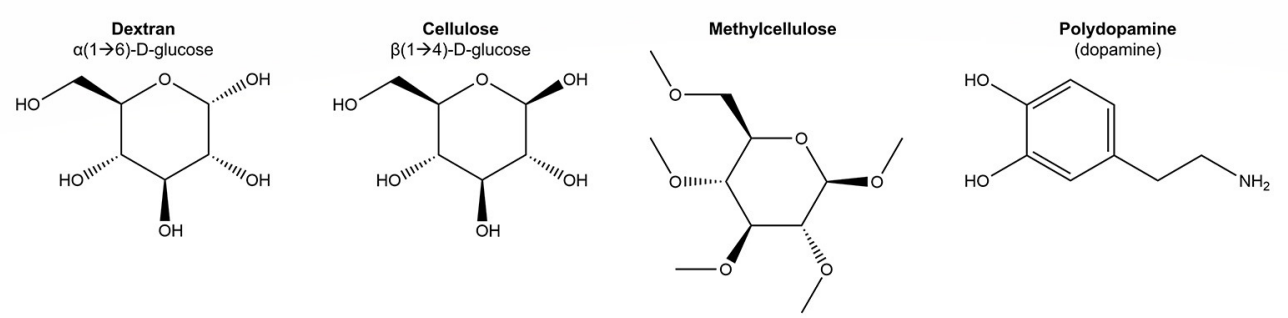<smiles>NCCN</smiles>

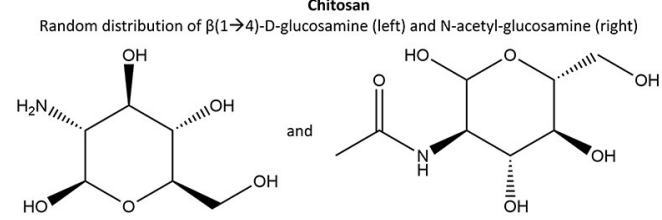

Chitosan

\section{Repeating Units for BIOPOLYMERS in Ocular Drug Delivery}<smiles>C1CCC1</smiles>

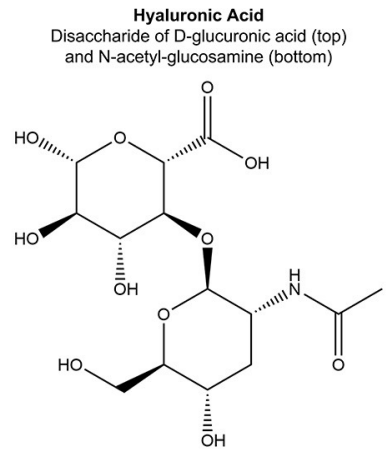
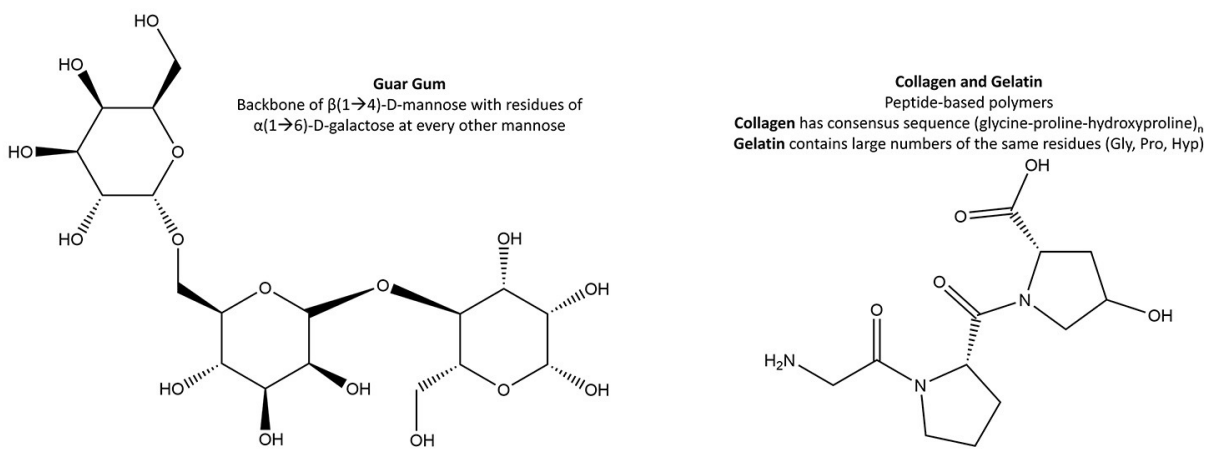

FIGURE 3 | Schematic of the repeating units that form the most noteworthy biopolymers used in ocular drug delivery.

syndrome (105). It is easily chemically crosslinked and has been experimentally investigated with chitosan, PLA/PLGA, and PEG for topical and intravitreal administration of ocular therapeutics (106). Recent experimental work has shown successful delivery of lutein, an antioxidant, from dextranchitosan crosslinked nanoparticles for topical administration (106). Dextran is also capable of drug conjugation for ocular delivery. Low molecular weight dextran has seen experimental use as a cationic DNA carrier for targeted gene therapy to treat X-linked juvenile retinoschisis. Recent work showed successful in vivo transfection and expression of a dextran-protamine-DNA complex adsorbed onto the surface of solid-lipid nanoparticles after intravitreal injection into rats (107).

Guar gum is a seed-derived polysaccharide with linear backbone chains of $\beta$-d-mannose units and branch points of $\alpha$-d-galactose units (108). As a biopolymer, guar gum is biocompatible, water soluble, a viscosity enhancer, capable of high degrees of swelling, mucoadhesive, non-ionic, and degradable by hydrolysis (109). The gelling ability of guar gum makes it beneficial as an additive to lubricating eye drops and is currently FDA approved for ocular use. Unfortunately, guar gum has limited solubility in alcohols and organic solvents and is unstable in solution. Derivatives such as hydroxymethylguar gum, hydroxypropyl-guar gum, and o-carboxymethyl o-hydroxypropyl-guar gum have been synthesized to improve solubility and stability (109). Hydroxypropyl-guar gum is found in several lubricating eye drops (110). Guar gum has been experimentally investigated to increase the bioavailability of natamycin for treatment of ocular fungal infection by integration onto PEG nanolipid carriers for controlled release from a carboxyvinyl polymer-guar gum-borate gelling system (110). Guar gum grafted PCL micelles have also been investigated for prolonged release of ofloxacin. Experimental guar gum-PCL micelles conjugated with retinol, biotinylated glutathione, and cell specific targeting agents before incorporation of ofloxacin showed drug release for at least 8 h (111).

Pullulan is a polysaccharide derived from the yeast Aureobasidium pullulans, composed of maltotriose units joined by $\alpha-1,6$ linkages (112). Pullulan is biocompatible, non-ionic, stable over a broad temperature and $\mathrm{pH}$ range, water soluble, insoluble in most organic solvents, easily processed, oxygen impermeable, viscosity enhancing, and biodegradable $(112,113)$. Pullulan has FDA GRAS status and has been used in many experimental biopolymer applications, including 
ocular drug delivery (114). The non-ionic nature of pullulan often requires derivation such as sulfation or amination to incorporate a charge for improved reactivity. Co-polymerization of pullulan with other biopolymers or synthetic polymers has shown promise for extending biodegradation rate compared to the polysaccharide alone. Examples include pullulan-gellan gum electrospun nanofibers for an in situ forming gel for extended topical therapeutic bioavailability (115). The gelation properties of pullulan in water make it popular for use in thin films and hydrogel inserts. Experimental work completed by Pai and Reddy (116). investigated the in vitro properties of a $10 \%$ pullulan gel insert intended for conjunctival drug delivery. The insert showed complete degradation in vitro and complete drug release within $3 \mathrm{~h}$ of application.

\section{Protein Biopolymers}

Collagen is a naturally occurring fibrous protein present in most connective tissue, including the cornea, sclera, lens capsule, and vitreous humor. Because it is naturally occurring, collagen is biocompatible, enzymatically degradable, can be relatively easily processed, and is widely available from primarily bovine and porcine sources. Recombinant collagen is also available, offering reduced dependence on animal sources through more consistent and safe production in plants and yeast cells (117). Collagen has a long established use in collagen shields for eye protection after ocular trauma or cataract surgery (118). More recent work utilizes collagen as a drug delivery device for encapsulated cell therapy via intravitreal injection, extended drug release via gels, or as a scaffold base for retinal tissue regeneration $(119,120)$. Current ocular drug delivery technologies that utilize collagen include Photrexa $\AA$, a collagen containing riboflavin ophthalmic suspension that when exposed to ultraviolet A light, crosslinks the biopolymer for treatment of progressive keratoconus (121).

Gelatin is a protein-based polymer formed from the irreversible hydrolysis of collagen. Like collagen, it is biocompatible, biodegradable, water soluble, gel forming and viscosity enhancing, readily available, and low cost, but shows advantages in lower gelation temperature and improved aqueous solubility $(122,123)$. It is derived from mammalian, avian, and ichthyoid collagen I sources, allowing for a broad range of available molecular weights, and is GRAS approved. Recombinant gelatin is also available to circumvent potential immunogenicity and provides access to specific gelatin molecular weights and isoelectric points (124). In ocular drug delivery, gelatin has seen applications in eye drops as a demulcent, in anteriorly and posteriorly applied hydrogels, nanoparticles for extended drug release, ocular tissue engineering, and siRNA carriers for gene therapy $(105,123,125-127)$.

\section{Other Biopolymers}

Polydopamine is a relatively recently investigated biopolymer, formed through oxidative polymerization of dopamine, one of the body's major neurotransmitters (128). Its biocompatibility and low toxicity have led to significant interest in its use in drug delivery, with particular attention paid to the development of coatings and nanostructures (128). These two applications have seen recent investigation as a novel method of ocular drug delivery. Liu et al. (129) developed an intraocular lens (IOL) with a self-polymerizing polydopamine coating capable of loading and eluting doxorubicin, preventing posterior capsule opacification (PCO) in rabbit models. Jiang et al. (130) developed polydopamine nanoparticles which showed effective loading and oxidative stress-dependent release of anti-VEGF in vitro. Recent findings that polydopamine coatings enhance nanoparticle mucopenetration may open the door to further applications of polydopamine in corneal drug delivery, especially as cellular uptake of these nanoparticles is also enhanced compared to uncoated nanoparticles (131). While polydopamine has only been under evaluation as a biomaterial since 2007, it has shown clear potential in ocular drug delivery, and will likely continue to mature with further research efforts (128). Several biopolymers used in ocular drug delivery are summarized in Table 2.

\section{POLYMERIC BIOMATERIAL FORMS}

\section{Micro- and Nano-Scale Technologies}

The versatility of biopolymers and synthetic polymers opens the door to many types and forms of biomaterials used as drug delivery vehicles to treat ocular diseases. Within the field of micro- and nanotechnology, there are a variety of drug delivery vehicles such as microparticles, nanoparticles, micelles, and liposomes. These drug delivery vehicles show significant promise in the eye due to their less invasive application approaches topically as well as ease of injection through small gauge needles $(44,142)$. These have also been explored for incorporation into drug-eluting contact lenses to facilitate topical delivery (143). Figure 4 presents several ocular drug delivery forms that utilize nanotechnology.

Microparticles are small-scale particles generally in the size range of $1-1,000 \mu \mathrm{m}$. Microparticles have been evaluated for ocular drug delivery for decades, and typically demonstrate higher drug loading capacity and release duration than nanoparticles due to the larger size of the particles, but a balance between drug loading and size considerations for injectability must be established. Several articles have focused on microparticles in the range of $1-50 \mu \mathrm{m}$ for intravitreal injection to balance these considerations (144). It has been recently proposed to use nanoparticles embedded in microparticles to overcome some of these challenges (145). Microparticles have also shown controlled variable monodispersity upon application, demonstrating versatility of this approach.

Nanoparticles are particles between 10 and $1,000 \mathrm{~nm}$ which can possess a surface charge, based on monomer properties, that allows for increased permeability or mucoadhesion of the therapeutic (146). Nanoparticles allow for drug delivery through encapsulation of the target therapeutic or surface loading through electrostatic interactions. Most of the biopolymers and synthetic polymers discussed in this review have been prepared as nanoparticles and extensively evaluated for drug delivery from contact lenses, intravitreal injection, topical, and suprachoroidal administration $(144,147,148)$. Nanoparticles have the advantage of being small enough to penetrate cells, maximizing therapeutic efficacy through targeted therapeutic release. Their small size also facilitates overcoming many of the barriers to ocular delivery. 
TABLE 2 | Summary of biopolymers used in ocular drug delivery and their properties.

\begin{tabular}{|c|c|c|c|c|}
\hline Polymer name & $\begin{array}{l}\text { Experimental/Clinical/FDA } \\
\text { approved biomaterial uses }\end{array}$ & GRAS & FDA approved indications & Pros/Cons \\
\hline Cellulose & $\begin{array}{l}\text { Hydrogels, films, nanoparticles, } \\
\text { inserts }\end{array}$ & Yes & Yes: food additive, topicals & $\begin{array}{l}\text { Pros: Biocompatible, nontoxic, high } \\
\text { molecular loading potential, nanomaterial } \\
\text { fabrication possible (132) } \\
\text { Cons: Low solubility (132) }\end{array}$ \\
\hline Chitosan & Nanoparticles, hydrogels & No & Yes: food additive, wound dressing & $\begin{array}{l}\text { Pros: Mucoadhesive, positively charged } \\
\text { at physiologic } \mathrm{pH}(133) \\
\text { Cons: Insoluble in neutral or alkaline } \\
\text { solutions, brittle in hydrogel form, strong } \\
\text { electrostatic behavior (134) }\end{array}$ \\
\hline Hyaluronic acid & $\begin{array}{l}\text { Hydrogels, nanoparticles, films, } \\
\text { tissue scaffolds }\end{array}$ & $\begin{array}{l}\text { No: classified as } \\
\text { medical device } \\
\text { currently }\end{array}$ & $\begin{array}{l}\text { Yes: cosmetic fillers, injectable for } \\
\text { osteoarthritis, topicals }\end{array}$ & $\begin{array}{l}\text { Pros: Biocompatible, mucoadhesive, } \\
\text { good viscoelastic behavior (133), naturally } \\
\text { occurring (135) } \\
\text { Cons: Difficult to functionalize, } \\
\text { challenging drug conjugation (136), effect } \\
\text { of molecular weight unclear (137) }\end{array}$ \\
\hline Carboxymethylcellulose & $\begin{array}{l}\text { Hydrogels, eye drops, } \\
\text { nanoparticles }\end{array}$ & Yes & Yes: disintegrant, dental devices & $\begin{array}{l}\text { Pros: Biodegradable, biocompatible, } \\
\text { capable of sustained release, } \\
\text { pH-sensitive (132) } \\
\text { Cons: Challenging to develop proper } \\
\text { viscous solutions (133) }\end{array}$ \\
\hline Gelatin & $\begin{array}{l}\text { Hydrogels, nanoparticles, films, } \\
\text { tissue engineering }\end{array}$ & Yes & Yes: medical devices, food additive & $\begin{array}{l}\text { Pros: Easily derived, biocompatible, rich } \\
\text { in ECM protein, less immunogenic, } \\
\text { transparent, low cost (123) } \\
\text { Cons: Strength depends on source and } \\
\text { processing conditions, still immunogenic, } \\
\text { challenging to safely crosslink (123) }\end{array}$ \\
\hline Pullulan & $\begin{array}{l}\text { Hydrogels, nanoparticles, eye } \\
\text { drops, fibers }\end{array}$ & Yes & $\begin{array}{l}\text { Yes: food additives, tablet coatings, } \\
\text { stabilizer, and thickener }\end{array}$ & $\begin{array}{l}\text { Pros: Easily derived, stable, good } \\
\text { film-forming properties, biodegradable } \\
\text { (116), nontoxic (139) } \\
\text { Cons: Unexpectedly slow diffusion (140), } \\
\text { requires functionalization to load drugs } \\
\text { (141) }\end{array}$ \\
\hline Polydopamine & $\begin{array}{l}\text { Nanoparticles, Intraocular } \\
\text { Lenses }\end{array}$ & Not evaluated & $\begin{array}{l}\text { No: Dopamine } \mathrm{HCl} \text { indicated for } \\
\text { correction of hemodynamic } \\
\text { imbalances }\end{array}$ & $\begin{array}{l}\text { Pros: Biocompatible, biodegradable, low } \\
\text { toxicity, excellent adhesion } \\
\text { Cons: Synthesis is challenging to control } \\
\text { and poorly understood, need for } \\
\text { investigation of toxicology, degradation, } \\
\text { elimination }\end{array}$ \\
\hline
\end{tabular}

While there are many advantages to nanoparticles and there has been a significant shift to focus on nanoparticles for ocular drug delivery in recent years, a nanoparticle ocular drug delivery system has yet to be commercialized (149).

Experimental systems include GB-102®, a PLGA microparticle-based drug delivery vehicle designed by Graybug
Vision for treatment of wet AMD and macular edema. The injectable drug depot is currently in clinical trials and has shown controlled release of sunitinib malate for up to 6 months post injection (32). POE-based nanoparticles maintained vitreous localization in rabbits after intravitreal injection for up to 14 days with minimal increases in IOP (150). Work by Fu et al. 


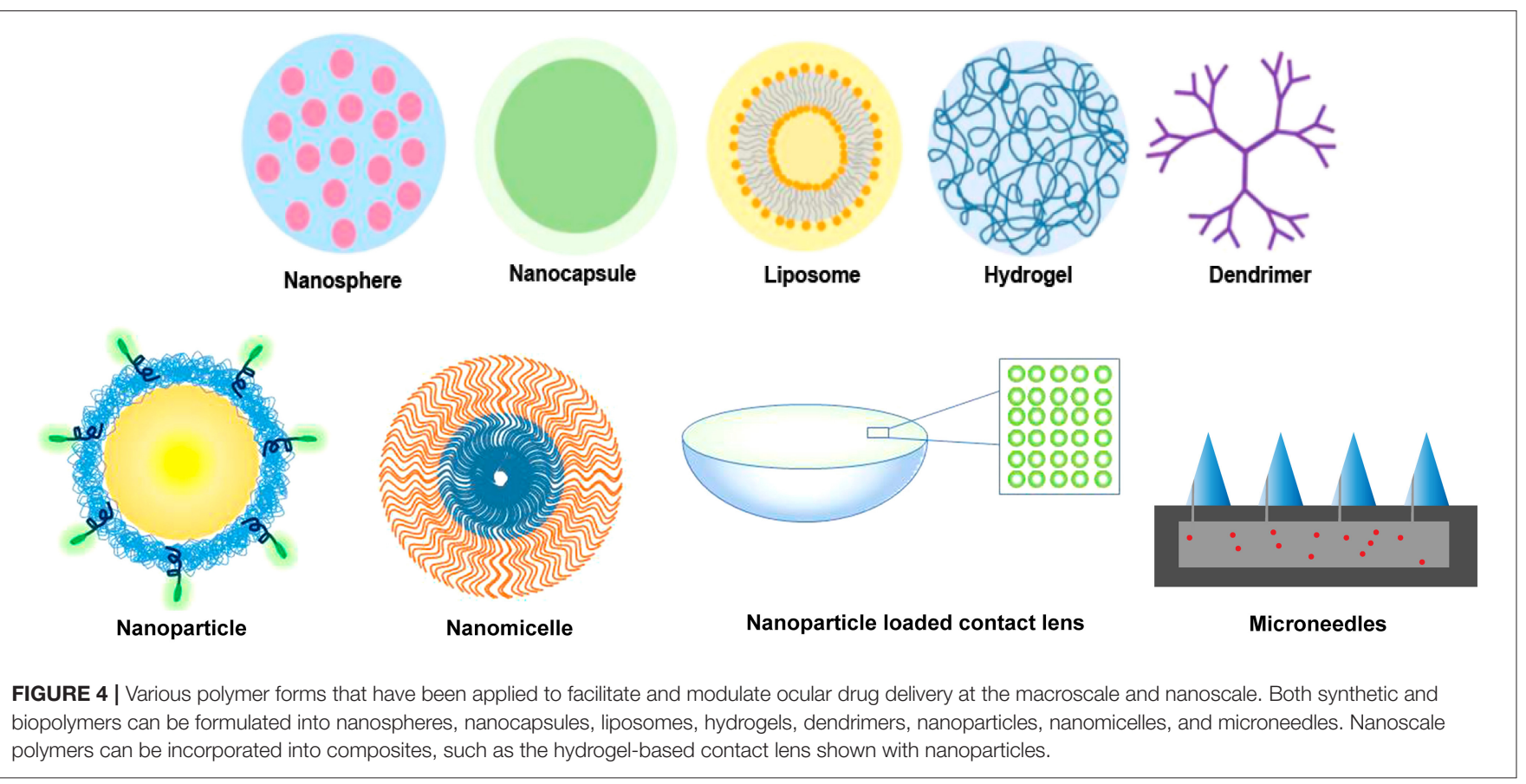

(151) developed poly(ortho ester urethane) nanoparticles that showed $\mathrm{pH}$-sensitive degradation properties and were efficient in delivering doxorubicin to in vitro tumor spheroids. Experimental work by Jiang et al. (60) utilized chitosan's cationic properties for intravitreal delivery of anti-VEGF bevacizumab through microparticles composed of a cationic chitosan core and PCL shell. Chitosan nanoparticles have also been evaluated for transscleral delivery of bevacizumab (152). Lu et al. reported bevacizumab-loaded chitosan nanoparticles for treating DR (153). Work by Dionisio et al. (154) modified pullulan through sulfation and amination to produce both negatively and positively charged pullulan-chitosan and pullulan-carrageenan nanoparticles for transmucosal drug delivery, while Garhwal et al. (155) integrated experimental pullulan-PCL nanospheres encapsulating ciprofloxacin into HEMA-based contact lenses for topical administration of antibiotics. Recent research on corneal applications of gelatin include positively charged gelatin nanoparticles for extended release of moxifloxacin (156). The particles showed in vitro drug release up to $12 \mathrm{~h}$ and showed in vivo antimicrobial properties superior to the market available

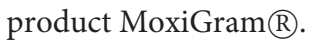

Micelles are core/shell structures formed by amphiphilic block copolymers with hydrophobic and hydrophilic domains, and are often $<100 \mathrm{~nm}$ in size. Polymeric micelles can enhance solubility of poorly soluble drugs and are being explored for use in promoting drug transport through the cornea and sclera (157). Micelles offer several advantages to enhance topical delivery, including thermodynamic stability, relative ease of preparation, high loading capacity, and lack of interference with optical properties of devices or solutions (143). These are likely to be adopted clinically due to relatively simple and inexpensive fabrication techniques (158). Micelles have been explored for several classes of therapeutics including cyclosporine, anti-inflammatories, immunosuppressants, anti-glaucoma drugs, antifungals, antivirals, and experimental antioxidants (159). Several stimuli-responsive poloxamers have been evaluated, including PF-127 for topical delivery of a hydrophobic drug to the anterior segment for treatment of allergic conjunctivitis (160), PF-68 for delivery of ferulic acid (161) or enhancing solubility of gatifloxacin in contact lenses (162), and their combination for delivery of antifungals (163). Triamcinolone acetonide delivery with PEG-block-PCL and PEG-block-PLA micelles was also evaluated (164). Other types of polymeric micelles evaluated include amino-terminated PEG-block-PLA and HPMC for delivery of tacrolimus (165). Chitosan has even been explored for micellar delivery (166), including delivery of dexamethasone (167), and HA has been conjugated to peptides to enhance solubility through micelles (97). Challenges that remain include improving micelle stability for longer shelf-life and therapeutic delivery duration. These factors can be controlled by polymer molecular weight, hydrophobicity/hydrophilicity, and block arrangement, with promise demonstrated with pentablock copolymer micelles (168). Further, micelles can be assembled into larger hydrogels to extend delivery (58).

While liposomes are not polymers, they have been used with polymers for ocular drug delivery. Liposomes have a cell membrane-like structure made from one or more phospholipid layers, enabling adhesion to cell membranes. They can be complexed with polymers to facilitate ocular drug delivery by improving liposome stability (148). Liposome conjugates evaluated for ocular drug release have included chitosan, silk fibroin, and PEG $(169,170)$.

These small systems have several advantages, including ease of injection, extended topical release, and enhanced permeability. 
Two key challenges are establishing long-term extended release and increasing drug loading efficiency. Other challenges include preserving therapeutic activity during preparation and loading of these delivery systems. That being said, injecting a microor nano-delivery system 2-3 times per year may still be a viable option for patients receiving more frequent intravitreal injections since injection would still be in office through a small gauge needle.

\section{Hydrogels}

Hydrogels consist of bound networks of synthetic and/or biologic hydrophilic polymers that absorb aqueous fluids. Many hydrogels exist specifically for intra- and extra-ocular applications ranging from contact lenses to vitreous substitutes. Hydrogels have also been used for drug delivery and/or cell encapsulation, and have been evaluated for use with optic nerve stabilization (171) and intraocular lens prosthetics (172). The large array of ocular applications may be attributed to both the hydrophilicity of hydrogels and the customizability of component polymers.

Hydrogels possess several modifiable and customizable properties such as degree of swelling, biodegradability/erosion, viscoelasticity, pore size, diffusion rate/flux, permeability, stimuli responsiveness, and drug/protein loading efficiency. Each of these characteristics may be directly or indirectly impacted by changing one or more of the following: degree of crosslinking (crosslinking density), monomer and polymer concentrations, and polymer type (atomic/molecular composition). The inherent hydrophilicity of hydrogels can provide systems with biological and mechanical stability in various ocular environments. A hydrogel's degree of crosslinking and hydrophilicity have a strong impact on the degree of swelling by their effect on variables such as pore size and diffusion rate/flux, which can be used to tune drug release. The aqueous environment in hydrogels allows investigators to mimic the extracellular matrix and tissues for cell delivery systems, may provide stability and improve cellular uptake for hydrophilic drugs, genes, and biologics. However, some therapeutics suffer reduced bioactivity in aqueous environments, and modifications may need to be made to incorporate hydrophobic drugs or prevent fast elution of hydrophilic drugs.

Due to the customizable nature of hydrogels and vast array of viable polymers, this area of research has potential for clinical translation and continued development. One specific area of recent growth for ocular applications is in situ hydrogel formation, where a hydrogel undergoes gelation (polymerization and/or crosslinking or self-assembly) in the ocular environment in response to specific stimuli (light, temperature, $\mathrm{pH}$, oxygenation, etc.). From intraocular applications such as intravitreal injections to topical treatments with films and inserts, hydrogels formed in situ show promise as a major player in the future of ocular drug delivery. In situ forming gels enable injection through smaller gauge needles, facilitating intraocular delivery in an outpatient setting. Furthermore, in situ formation can enable conformal coating of curved surfaces like the cornea, enabling direct contact and more consistent drug delivery.
Xie et al. (173) developed a nanoparticle/hydrogel composite for the sustained release of an anti-tumor therapeutic to the posterior segment of the eye. The hydrogel, composed of collagen II and sodium hyaluronate, was formed in situ following injection in to the vitreous and in response to physiological temperature stimuli. Thermo-responsivity was attributed to a thermo-responsive crosslinking reaction at $37^{\circ} \mathrm{C}$ between amine groups of collagen and succinimidyl groups of the additive 8-arm PEG succinimidyl glutarate (tipentaerythritol). Another injectable hydrogel was presented by Osswald et al. (51) to deliver anti-VEGF to the choroid via intravitreal injection. This hydrogel consisted of poly(N-isopropylacrylamide) (PNIPAAm) and poly(ethylene glycol) diacrylate (PEGDA) and utilized the properties of PNIPAAm to create a thermo-responsive in situ forming hydrogel. In 2016, researchers developed a hydrogel that underwent gelation upon exposure to aqueous conditions (174). This unique in situ gelation method was the product of hydrophobic interactions between poly(ethylene glycol) methacrylate (PEGMA) and vitamin E methacrylate leading to the formation of physical crosslinks. This hydrogel's chemistry and crosslinking ability has potential in generating hydrogels capable of delivery of hydrophobic drugs.

Drug delivery coordinated with tissue replacement, such as intraocular lens implantation and vitreous substitution, is a relatively recent area of research. This work shows great promise by potentially offering a reduction in frequent administration or procedures and mitigation of post-operative complications. Tram et al. (175) proposed a solution for combatting cataract formation following vitrectomy by loading PEG-based hydrogel vitreous substitutes with the antioxidant ascorbic acid. Building off of that research, they found that glutathione may be a useful addition to ascorbic acid in ocular drug delivery (13). Polymer coatings for IOLs, made of polydopamine or synthetic polymers, are being evaluated to reduce complications after cataract surgery from infection and PCO $(129,176)$.

While significantly less invasive than injections and tissue replacement strategies, topical hydrogel drug delivery solutions present their own challenges, requiring prolonged contact with tissues of interest and firm shape retention. One example of a topical in situ forming hydrogel was reported by Anumolu et al. (177) to deliver doxycycline to the cornea using PEG octamer hydrogels (177). The hydrogels were $\mathrm{pH}$-responsive, undergoing shape-retaining gelation within seconds of application. Another example of a viable in situ forming hydrogel used for sustained drug delivery was recently published by El-Feky et al. (178), who installed the gel into the inferior conjunctival fornix to deliver nifedipine for glaucoma treatment (178). Hydrogels were created using poloxamer 407 (P407) and HPMC, utilizing properties of P407 to incorporate thermo-responsiveness into the hydrogels. Fedorchak et al. (179) made use of a thermo-responsive PNIPAAm hydrogel eyedrop containing drug-loaded PLGA microspheres to achieve long-term delivery of brimonidine for glaucoma treatment, showing efficacy in rabbit models out to 28 days after administration.

In situ gelation provides a drug delivery solution that is tailored to the patient's ocular geometry and has great potential in reducing both treatment frequency and procedure invasiveness. 
Opportunities for innovative hydrogel solutions for ocular drug delivery are ever-growing, opening doors for many more future research projects and likely commercial translation in the near future.

\section{Fibers, Films, Rods, Extrusions}

Processing polymers into fibers, films, rods, or extruded forms allows various alternative configurations for drug delivery systems. These delivery methods and geometries may even be interconnected. For example, fibers may be formed via electrospinning to create a rod-shaped implant, or the fibers may be spun into a sheet and hydrated to form a film.

Kelley et al. (180) detailed and compared production methods for hot-melt extrusion manufacturing of dexamethasoneloaded injectable intravitreal implants. The extruded rods were composed of PLGA with varying weight percentages of acidand ester-terminated PLGA to control the implant degradation and drug release rate. OZURDEX $\AA$ (Allergan) is an FDAapproved intravitreal implant that employs extruded PLGA (NOVADUR \& technology) for sustained dexamethasone release through biodegradation (181).

One method for producing fibers is electrospinning. A recent study experimented with various configurations for conjunctival fornix inserts for sustained delivery of besifloxacin to the cornea for treatment of bacterial keratitis (182). The inserts, synthesized via electrospinning, were prepared as fibers of PCL and PEG and then coated with biopolymers-either sodium alginate or thiolated sodium alginate-to confer mucoadhesion. Another ocular insert composed of electrospun PCL and intended for insertion into the conjunctival fornix was developed to deliver fluocinolone acetonide to the retina and was evaluated in pre-clinical studies (183). PCL and chitosan capsules have also been prepared via electrospinning to fabricate a hollow bilayered design for intravitreal injection (61). Delivery systems designed with electrospun nanofibers present two specific advantages: tunable device porosity for controlled drug diffusion and a high ratio of surface area to volume for increased chemoadsorption (61).

Electrospun conjunctival fornix inserts were also investigated for the delivery of triamcinolone acetonide to the anterior and superficial segments of the eye (184). Investigators analyzed properties and release profiles of nanofiber formulations with varying concentrations of PVA, poly(vinylpyrrolidone) (PVP), zein/eudragit, and chitosan, identifying an optimal formulation of only PVP and chitosan.

Electrospinning has also been applied to develop both in situ-forming and pre-hydrated hydrogel systems. Göttel et al. (139) presented an in situ gelation system that begins as a curved lens of electrospun pullulan and gellan gum fibers. Upon application to the ocular surface, the fibrous lens hydrates to form a film/hydrogel. A different study utilized electrospun PVP and HA nanofibers to develop hydrogels for drug delivery (185). This study focused on developing an ocular insert to deliver ferulic acid and Epsiliseen $(\mathrm{R}-\mathrm{H}$ for treating ocular surface conditions. PVP was employed to enable electrospinning of HA while HA was the polymer responsible for the drug delivery mechanism.
Films are comparable to hydrogels for drug delivery as they hydrate to form an aqueous system. They also show potential in drug delivery, particularly for topical applications. A porous resorbable film was recently investigated as a bandage contact lens following corneal injury (186). The films were composed of bovine serum albumin (BSA) structural nanofibrils and the antioxidant kaempferol.

One recent advancement in fiber and film technology is the PRINT $\AA$ technique. This technology allows researchers to precisely control a film's shape, size, surface properties/functionality, chemical composition, porosity, and moduli $(187,188)$. Researchers have employed PRINT $\AA$ to customize drug delivery systems on the nanoscale-level to control for release profiling/kinetics and environment of application (189). The technology can use an array of biopolymers and therapeutics including peptides, nucleic acids, and antibodies $(146,187)$. PRINT $\AA$ has been used to develop subconjunctival implants, intracameral implants, intravitreal implants, nano-and micro-suspensions, etc (190). One recent development with PRINT $\AA$ technology is the AR13503 (Aerie Pharmaceuticals) implant, which utilizes PLGA, PDLA, and PEA to control delivery to the retina for more than 2 months and is in phase 1 clinical trials (190-193). Another delivery system developed with PRINT $\AA$ is an Envisia Therapeutics implant (ENV515) currently in phase 2 clinical trials (194). Results thus far suggest that ENV515 is effective in lowering IOP for 28 days $(195,196)$. Results from a 12 -month study found $25 \%$ IOP reduction compared to topical ophthalmic solution (195). PRINT® shows great promise for its ability to customize polymer-based ocular drug delivery systems at the nanoscale level.

Polymer processing techniques are well developed in other applications and are beginning to emerge in ocular drug delivery systems. These processing techniques will be required for manufacturing of several ocular drug delivery devices and give potential to explore innovative new delivery systems using already approved polymers.

\section{ADMINISTRATION METHODS}

\section{Eyedrop Delivery}

Eyedrops have seen widespread usage for delivering a variety of medications for ocular disorders, thanks to their ease of use, low cost, and relatively good patient compliance $(142,197)$. However, in recent years, their limitations as a drug delivery system have led to significant research effort invested in improving their capacity or developing more efficient alternatives (198). While eyedrops offer excellent delivery efficiency for topical diseases of the eye, their efficiency significantly declines when used to deliver pharmacologic agents to certain tissues in the eye. By some estimates, as little as $1-5 \%$ of an eyedrop's drug content can reach the anterior segment of the eye due to the barriers it faces in passing through the cornea to the aqueous humor $(142,158,199)$. First among these is the rapid turnover of the tear film on the cornea, which leads to a significant fraction the eyedrop's volume following the tear film into nasolacrimal drainage and systemic 
circulation (200-202). By some estimates, as much as $80 \%$ of the tear film's volume can be turned over in a minute when eyedrops are applied to the eye, leading to significant loss of dose volume (200). This lost drug dosage then enters systemic circulation, where it may be metabolized before reaching ocular tissue and risks triggering systemic side effects that compromise patient health (202). Any drug not cleared via tear film drainage must still penetrate corneal tissue in order to reach the anterior chamber and have a therapeutic effect on ocular tissue. The structure of corneal tissue makes it difficult for both hydrophilic and lipophilic molecules to pass through. The corneal epithelium admits only lipophilic drugs smaller than $10 \AA$ through cellmediated transport mechanisms, and forces hydrophilic drugs to diffuse through paracellular pathways blocked by tight junctions $(19,158)$. The corneal stroma, meanwhile, is highly hydrophilic, slowing the movement of the lipophilic drugs that pass the epithelium while allowing freer movement of the few hydrophilic molecules that enter (158).

Despite these challenges to drug retention and penetration, eyedrops are still favored for the treatment of diseases in the anterior segment of the eye. Their ease of delivery has also made them attractive for delivery to the posterior of the eye, with researchers investigating a variety of eyedrop formulations with improved drug retention and penetration characteristics, with some working toward eye drop formulations for posterior ocular delivery to overcome the limits of injections (201, 203-207).

The combination of rapid clearance and the extreme difficulty of corneal penetration has led to significant research efforts aimed at increasing the delivery efficiency of eyedrops. One of the earliest options explored was to simply increase the concentration of drug delivered in the eyedrop solution, overcoming delivery barriers through essentially brute force. However, this option presents its own challenges, as such high drug doses and accompanying polymer and preservative exposure could cause local irritation or toxicity in patients (207-210). In addition, the higher drug dose per eyedrop leads to higher doses draining to the bloodstream, potentially exacerbating systemic side effects (208). As an alternative to increasing dose per eyedrop, some medications instead recommend increasing the frequency of eyedrop administration. However, this presents its own challenges, as higher frequency administration has been linked to significant reductions in patient compliance with treatment regimens $(207,211)$. Patients with physical or visual impairments, as well as children who are unable to administer eyedrops to themselves, may be especially non-compliant, as eyedrops rely on self-application to have an effect (210). In addition, frequent repeated application of eyedrops may still lead to local and systemic side effects associated with high dosing (207).

Because of these continued challenges in increasing delivery efficiency of eyedrops, modern research has investigated a variety of polymer-based solutions for enhancing drug penetration and residence time in the anterior eye. One solution is the development of polymer nanocarriers with mucoadhesive capabilities. These nanoparticles can entrap themselves in the mucus layer that covers the cornea, with some even capable of penetrating corneal tissue to enter the aqueous humor thanks to their small size $(158,200,202,205)$. Mucoadhesion lengthens the residence time of drug delivery systems significantly, allowing them to more effectively release their drug payload for uptake by ocular tissue. Corneal penetration is an even more desirable outcome, as the ability to effectively penetrate the cornea using a drug carrier provides immense opportunities for delivery to intraocular spaces. Recent research efforts have developed chitosan and PLGA nanoparticles capable of reaching the retinal surface, a demonstration of how nanoparticles can help solve the challenge of developing eyedrops capable of posterior ocular delivery $(211,212)$. Another option is the addition of polymer viscosity enhancers and gelling agents such as xanthan gum, which increase the residence time of an eyedrop atop the cornea, thereby giving more time for the drug payload to begin penetrating corneal tissue $(19,213)$. Both of these solutions make use of a variety of polymers. While they still face significant challenges in successful implementation and translation from laboratory to clinical use, several preclinical studies are making use of gelling systems to improve drug delivery efficiency through eyedrops. One interesting recent development has been investigation into thermosensitive polymers that form gels at physiologic temperatures $(207,214)$. These polymers could allow future eyedrops to be administered in solution at room temperature, then form a hydrogel reservoir on contact with the warmer tissue of the eye, providing an easily administered long-lasting form of ocular drug delivery.

\section{Subconjunctival Injections and Implants}

Injection of pharmacologic agents presents an attractive alternative route for the delivery of drugs to ocular tissue. Injection into the subconjunctival space specifically allows drugs to be released next to the sclera and avoid corneal barriers to entry (202). Drugs are able to easily penetrate the more permeable scleral layer, potentially enabling significantly more efficient delivery to the interior of the eye, particularly the posterior segment (197, 201, 209, 213). While subconjunctival drug injections and implants necessitate a relatively more invasive procedure than eyedrops, they offer the potential of prolonged drug delivery compared to eyedrops, potentially lasting months between injections or implant replacements $(19,199)$. This would represent a significant advantage in patient compliance, as a minimally invasive injection or implantation procedure every few months is significantly easier to maintain compared to daily eyedrop administration regimens $(19,158)$. This method is not without challenges, however, as the subconjunctival space, while not as severely drained as the anterior surface of the eye, is still rich in drainage routes. Conjunctival and scleral blood vessels, as well as lymphatic drainage, will interfere with delivery and cause some of the administered dose to enter systemic circulation rather than penetrate the sclera and enter the eye $(201,202)$. In addition, the choroidal tissue in the eye poses an additional barrier to lipophilic drug delivery, as this tissue can bind lipophilic drugs (213).

The significant potential of subconjunctival delivery to bypass the challenges of eyedrop administration in a minimally invasive manner has led to research efforts focused on overcoming the challenges of clearance and penetration while extending 
the duration of drug release after implantation or injection. Polymer solutions for these problems include polymer microand nano-particles which, similar to their role in eyedrop formulations, help improve drug residence time near ocular tissue and assist in penetrating the scleral barriers to ocular entry, thereby increasing the drug dose delivered (158, 201, 202). Alternatively, subconjunctival injections of drug-loaded hydrogels composed of polymers such as PEG, PLGA, and HA can create a reservoir capable of extended release over a course of weeks or months, offering a more easily prepared alternative to micro- and nanoparticle systems (197, 208). Finally, polymeric subconjunctival implants offer a more stable platform for drug delivery through the subconjunctival space, with research publications describing devices made of PDMS, PLGA, and polyurethane among others (19, 197, 209). Animal studies into the use polymer-based subconjunctival drug delivery systems have found promising initial data, with favorable biocompatibility and safety results for polyimide and PLGA implants and evidence of extended-release efficacy for PLGA microspheres in the subconjunctival space $(215,216)$. Further research into delivery through the subconjunctival space is likely to offer significant potential for improvement of drug delivery compliance and outcomes. Many of these research efforts may benefit from prior developments in subconjunctival drainage devices designed to relieve IOP and assist in glaucoma treatment, as numerous polymer drains have already received approval for market use (217).

\section{Suprachoroidal Injections}

Another alternative route for drug delivery is injection to the suprachoroidal space, a thin layer of tissue between the sclera and choroid of the eye (218). In theory, injections into this space could quickly spread across the inner surface of the eye, allowing rapid access to the posterior tissues of the eye with limited loss to the vitreous humor $(201,218)$. This would provide a highly specific pathway for delivery to these tissues with minimized adverse effects from off-target delivery and significantly lower invasiveness compared to intravitreal injection (213). However, the suprachoroidal space is extremely delicate, with only $30 \mu \mathrm{m}$ of tissue thickness in the region and a recommended maximum injection volume of only $200 \mu \mathrm{l}$ (218). Higher volumes than this risk causing choroidal edema and detachment (218). In addition, as this space has been relatively underexplored, there is a significant chance that yet-undiscovered safety challenges may emerge with the use of a broader range of polymers and injection systems. Perhaps because of these significant challenges to safe and accurate delivery, there has been relatively minimal exploration and characterization of the suprachoroidal space, with early studies beginning only in the mid-2000s and testing of suprachoroidal delivery in animal models of ocular disease by the early 2010s $(219,220)$.

Einmahl et al. investigated the suprachoroidal space's tolerance of POE in rabbit models, finding no evidence of complications or intolerance over the 3 weeks the polymer remained in the space (221). In recent years, microneedle-based injections to deliver drug-laden solutions into the suprachoroidal space have been frequently explored, as they are a minimally invasive method with less risk of complications and rapid sealing of the injection site (201). Polymers investigated in these suprachoroidal microneedle injections serve a variety of roles, from simple injection excipients to the focal point for investigation. Chiang et al. (222) used injections of CMC to form hydrogels capable of swelling after injection to evaluate their effect on the thickness of the suprachoroidal space. They also explored the use of polymers as injectable drug delivery excipients by evaluating the distribution of FITC-labeled CMC and HA in the suprachoroidal space following microneedle injection (223). One possible innovation in this area is the

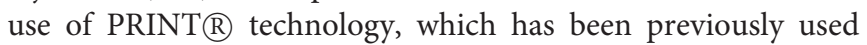
to produce microneedle arrays for transdermal drug delivery (224). This application of PRINTß has been licensed for use by Aerie Pharmaceuticals and may be employed for suprachoroidal microneedle systems in the future (189). Jung et al. (225) investigated the utility of HA hydrogels as a means of directing suprachoroidal drug delivery, using the hydrogel's swelling behavior to push drug-laden polymer microparticles toward the posterior ocular tissue. These investigations demonstrate novel potential applications of polymers in ocular drug delivery and may provide a foundation for future innovation in suprachoroidal delivery.

\section{Intravitreal Injections and Implants}

While subconjunctival and suprachoroidal injections and implants offer a more efficient alternative to eyedrops for drug delivery to the eye and are more effective at both anterior and posterior delivery, they are still subject to limitations due to the tissue and drainage barriers they face when releasing drugs (201). Delivery directly to the vitreous humor bypasses corneal and scleral tissue barriers and ensures high drug delivery efficiency, drug bioavailability, and precise control of therapeutic concentrations, especially to tissues in the posterior eye $(20,142,200,213)$. For this reason, in spite of its invasive nature, intravitreal injections are currently a popular choice for drug delivery to the posterior segment. However, injections of drug solution without controlled release systems still face rapid clearance in the vitreous, necessitating frequent injections to maintain therapeutic levels of drug in the eye $(213,226)$. This is problematic for patients, as this procedure requires ophthalmologists to administer the injections and risks significant side effects. These range from more manageable issues, such as elevated IOP and endophthalmitis, to severe and potentially vision-altering side effects such as retinal detachment and intravitreal or subconjunctival hemorrhage (142, 197, 201, 203). In addition, drug that has been injected must still contend with diffusion through the vitreous humor to reach target tissues, a process made more difficult by rapid clearance due to vitreal circulation, the charge of vitreal fluid interfering with the diffusion of charged molecules, and the vitreous humor's extracellular matrix hampering large molecule movement (197, 227). While this method does offer some advantages over topical and subconjunctival delivery, these challenges limit its effectiveness in current drug delivery applications.

To overcome these challenges, significant effort has been invested in the development of intravitreal drug delivery systems. 


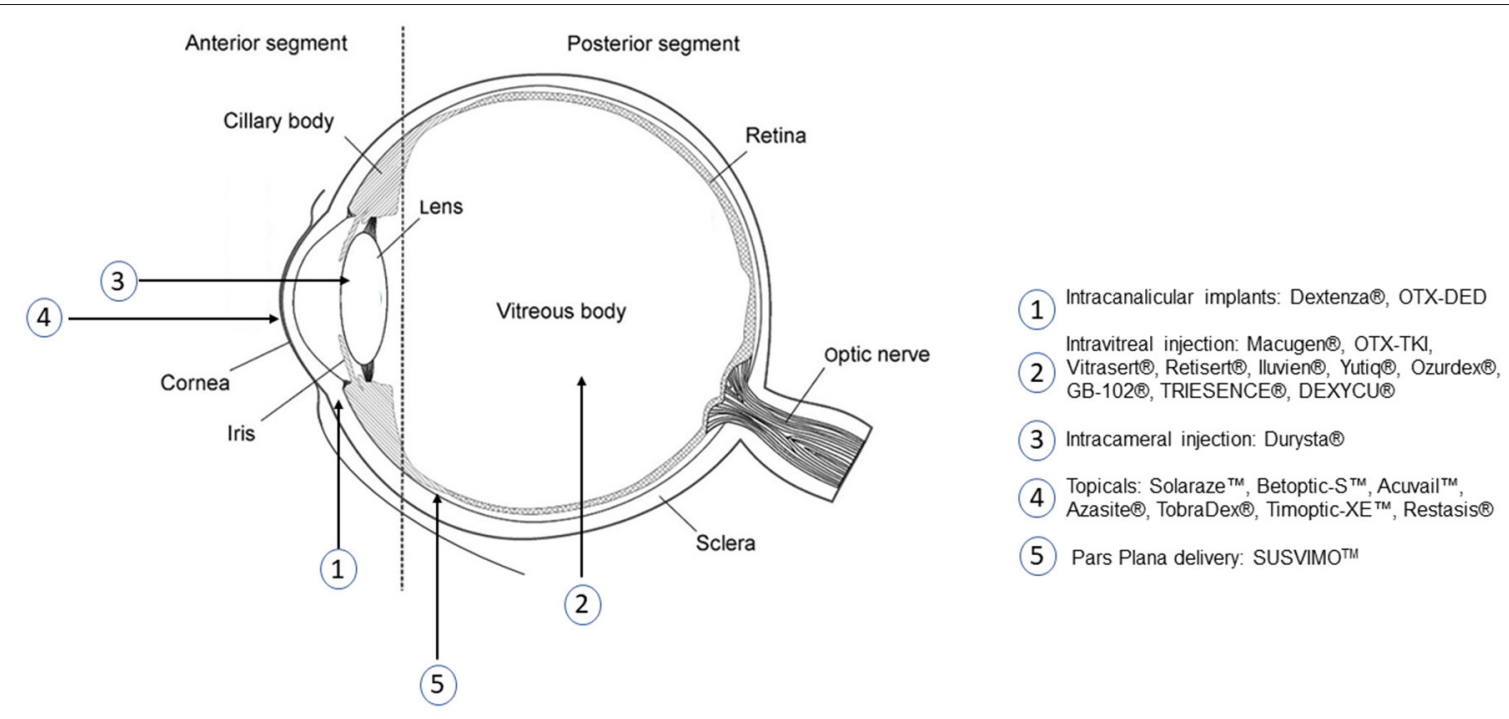

FIGURE 5 | Administration location of several FDA approved ocular drug delivery systems that use polymers.

Recent examples include a thermoresponsive polymer made of a combination of pentaerythritol, lactic acid, and $\varepsilon$-caprolactone functionalized with PEG and another thermoresponsive hydrogel made of PEG-poly(serinol hexamethylene urethane), which can be injected into the intraocular space to serve as a controlled-release system for extended drug delivery (226, 228). Researchers have also investigated a variety of polymer nanoparticles, using materials such as PCL and PLGA to develop drug-loaded nanoparticles for intravitreal injection $(226,227)$. Others have developed intravitreal implants out of materials such as PLGA, silicone, polyimide, and PVA. The goals of these systems are to increase the duration of drug release, thereby reducing injection frequency and its associated risks without exposing the eye to additional risks from the polymers themselves. This is a delicate balance, which will require significant research effort to maintain, but the potential benefits of an extended-release intravitreal drug delivery system are highly promising. Several labs are investigating additional polymer systems for intravitreal use. This includes our work developing polydopamine nanoparticles for anti-VEGF delivery, as well as efforts by other labs developing technologies such as phase-inversion mixtures of polymer and solvent, PEGylated siloxanes, and NIPAAmbased thermoresponsive polymers for intravitreal (130, 229, 230). Some of these systems are currently being translated for commercial use, such as ReVana Therapeutics' EyeLief ${ }^{\mathrm{TM}}$ and OcuLief ${ }^{\mathrm{TM}}$ injectable polymers (231). One system with particularly promising results is the Genentech Port Delivery System, SUSVIMO ${ }^{\mathrm{TM}}$ a reloadable port composed of a polysulfone body coated in silicone, which recently received FDA approval for delivery of ranibizumab for the treatment of wet AMD $(232,233)$. Figure 5 contains a schematic of some of the FDA approved polymeric biomaterial products and administration location.

\section{REGULATORY STATUS OF OCULAR DRUG DELIVERY SYSTEMS}

While there is significant effort being invested in the development of polymer-based ocular drug delivery systems, a key challenge is the translation of these systems to clinical use. A number of products have successfully reached the market over the last few decades, with all four administration methods discussed previously having at least one FDA-approved drug delivery system that includes polymers to enhance their function. Notable examples are shown in Table 3. Eyedrops, the most mature drug delivery platform of the four, understandably have a significant number of polymer products, with numerous formulations approved for the treatment of diseases such as glaucoma, bacterial conjunctivitis, and uveitis $(200,213)$. Most make use of these polymers to increase the drop's residence time and release efficiency. Other applications such as polymer nanocarriers and thermosetting gels are still under investigation to evaluate their utility in extending the duration of eyedrop drug release and drug penetration $(200,202)$. Research into using eye drops for posterior segment delivery could have significant implications in the field of ocular drug delivery.

In the intravitreal space, progress has been much slower, with only seven intravitreal polymer systems obtaining regulatory approval for use with a small set of diseases (46, 200, 213 , 244). These seven, the Iluvien $($, Ozurdex $($, Retisert $\AA$, Vitrasert $($, Yutiq $($, Dextenza, and DEXYCU $($ implants, use a variety of polymers in their construction. Iluvien $\mathbb{R}$

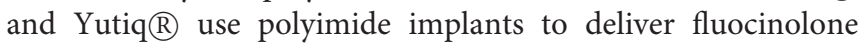
acetonide (46, 235). Ozurdex $\AA$ uses a PLGA matrix that degrades to release dexamethasone (236). Retisert $(\mathrm{A}$ contains a fluocinolone acetonide tablet in a silicone/PVA elastomer

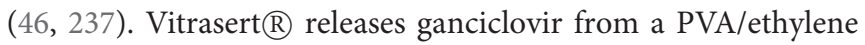
vinyl acetate system (200). Dextenza suspends dexamethasone 
TABLE 3 | Polymer-based ocular drug delivery systems with FDA approval.

\begin{tabular}{|c|c|c|c|c|}
\hline Product & Polymer(s) & Pharmaceutical & Delivery route & Indication \\
\hline TRIESENCE ® (234) & Carboxymethylcellulose & Triamcinolone Acetonide & Intravitreal Injection & $\begin{array}{l}\text { Uveitis, temporal arteritis, } \\
\text { sympathetic ophthalmia }\end{array}$ \\
\hline Ozurdex® (236) & PLGA & Dexamethasone & Intravitreal Implant & $\begin{array}{l}\text { Diabetic macular edema, macular } \\
\text { edema, uveitis }\end{array}$ \\
\hline Vitrasert (200) & PVA/Ethyl Vinyl Acetate & Ganciclovir & Intravitreal Implant & Retinitis \\
\hline Dextenza (238) & PEG-Fluorescein & Dexamethasone & Intravitreal Implant & Postsurgical ocular inflammation \\
\hline DEXYCU® (46) & Acetyl triethyl citrate & Dexamethasone & Intravitreal Implant & Postsurgical ocular inflammation \\
\hline Durysta ${ }^{\mathrm{TM}}$ (48) & PLGA/PGA/PEG & Bimatoprost & Intravitreal Implant & $\begin{array}{l}\text { Open angle glaucoma, ocular } \\
\text { hypertension }\end{array}$ \\
\hline Optive (85) & $\mathrm{CMC}$ & $\mathrm{CMC}$ & Eyedrop & Dry Eye Syndrome \\
\hline Optive Fusion (85) & $\mathrm{HA} / \mathrm{CMC}$ & $\mathrm{HA} / \mathrm{CMC}$ & Eyedrop & Dry Eye Syndrome \\
\hline Restasis $®$ (77) & PAA & Cyclosporine & Eyedrop & Dry Eye Syndrome \\
\hline Neopt (85) & $\mathrm{HA}$ & $\mathrm{HA}$ & Eyedrop & Dry Eye Syndrome \\
\hline Vismed Multi (85) & HA & $\mathrm{HA}$ & Eyedrop & Dry Eye Syndrome \\
\hline Tears Naturale $®(240)$ & HPMC, Dextran 70 & HPMC & Eyedrop & Dry Eye Syndrome \\
\hline GenTeal® (240) & HPMC & HPMC & Eyedrop & Dry Eye Syndrome \\
\hline Betoptic-S TM (200) & Polystyrene-divinylbenzene & Betaxolol & Eyedrop & Open angle Glaucoma \\
\hline Acuvail $^{\mathrm{TM}}(200)$ & $\mathrm{CMC}$ & Ketorolac Tromethamine & Eyedrop & $\begin{array}{l}\text { Postsurgical ocular pain and } \\
\text { inflammation }\end{array}$ \\
\hline Azasite® (200) & Polycarbophil & Azithromycin & Eyedrop & Bacterial conjunctivitis \\
\hline
\end{tabular}

in a PEG-fluorescein hydrogel (238). Finally, DEXYCU $®$ makes use of acetyl triethyl citrate gel to deliver suspended dexamethasone (46). Four of these seven are non-degradable implants; Ozurdex $\AA$, Dextenza, and DEXYCU $\AA$ are capable of resorption into the tissue of the eye. This helps to control drug release rate by providing a constant polymer membrane through which drug diffuses into the intravitreal space. However, it also presents challenge of implant removal and replacement once its therapeutic payload is expended, requires surgery and may incur additional health risks for the patient. A search of the Drugs@FDA database indicates that Iluvien, Ozurdex, Yutiq, DEXYCU, Dextenza, and Retisert remain available by prescription, while Vitrasert has been discontinued in the US. There are many more polymer implants in various phases of clinical and laboratory research making use of materials such as PLGA and PEG, indicating that there is significant progress yet to be made in clinical deployment of polymer systems in the vitreal space $(20,200,226)$. In addition to recently approved systems such as the Genentech Port Delivery system, Kodiak is currently in phase 3 trials using an injectable biopolymer-antibody conjugate for the treatment of wet AMD and DME, while Aerie is testing biodegradable polymer implants for DME in a phase 2 trial $(245,246)$. With ongoing efforts in the development of intravitreal microparticles, nanoparticles, and injectable hydrogels, it is likely that intravitreal drug delivery options available to patients and clinicians will become significantly more diverse in the coming years $(20,142,227,247)$.

Subconjunctival drug delivery is a route that has only recently begun to be explored. Despite this, there has been progress in the development of subconjunctival polymer drug delivery systems, with the Ologen $\AA$ and Xen Gel systems using collagen to construct implants and research efforts into other polymers such as PLGA showing promising results for implant performance $(197,201)$. However, these implants may pose challenges with discomfort and potential complications, leaving significant room for improvements in the future $(197,199)$. 
Research into other polymer systems for subconjunctival delivery is an emerging area, with several research efforts investigating alternative implant polymer compositions, nanoparticle-based delivery systems, and injectable hydrogels for use as drug reservoirs in the subconjunctival space (197, 199, 209, 248250). However, many of these are still in the early phases of development, and are likely to require further research showing safety and biocompatibility, as well as well-developed animal studies to show efficacy, before they can be put into clinical trials (197).

Finally, while the suprachoroidal route is the least explored for ocular drug delivery, products such as the XIPERE ${ }^{\mathrm{TM}}$ system's injectable triamcinolone acetonide solution are nearing market approval $(201,251)$. In addition to these promising developments in suprachoroidal injections, there are several choroidal devices that have found success in clinical uses. In particular, choroidal shunts made of polymers for the reduction of IOP in glaucoma patients have been the subject of significant investigation as an alternative to subconjunctival drainage, and choroidal port delivery systems have been successful in clinical trials evaluating their efficacy for drug delivery in retinal diseases $(19,252$, 253). The ability to build on these innovations and incorporate polymers used in other ocular drug delivery systems will provide a valuable and viable path forward for the development of polymer systems for suprachoroidal injection.

Part of the reason that only a small number of synthetic polymers are being used in ocular drug delivery applications is regulatory hurdles. Even using FDA-approved therapeutics, these drug-device combinations must perform more testing than traditional medical devices through a $510(\mathrm{k})$ approval pathway with the FDA. Other challenges include the fact that the polymer delivery system likely changes the required therapeutic dose, generally leading to less therapeutic need due to reduced therapeutic waste. For example, when polymer delivery systems are employed, drug retention on the cornea improves significantly compared to non-polymer delivery systems (158). The reduction in necessary dose is not usually known until preclinical or clinical studies are conducted. Dosing at lower levels can be estimated using effective therapeutic concentrations, but long-term stability and therapeutic shelf-life are still concerns that must be addressed prior to approval.

\section{FUTURE DIRECTIONS}

While polymers have been used in ocular drug delivery for decades, with the first polymer intravitreal implants receiving approval in 1996 and topical applications making use of them since the 1970s, many applications of polymers in ocular drug delivery systems are still in the early stage of development, with significant untapped innovation that could lead to drastic improvements in the capability, quality, and ease of these treatments (213). The next decade will see a large increase in preclinical and clinical trials of polymer-based ocular drug delivery systems. Eyedrop systems have found some success in the development and clinical approval of polymers designed to extend the residence time of the drop on the corneal surface (207). However, continued challenges in corneal penetration leave room for further exploration. Ongoing research into the translation of technologies such as nanomicelles and gelling agents to clinical applications seeks to further improve the efficacy of eyedrops as a delivery system (110, 254). Topical delivery to treat posterior segment diseases is also an area worth exploring to benefit patients. Intravitreal injections and implants have begun to embrace polymers as a method of increasing delivery duration with the development of polymer implants. Intravitreal implants, however, can be difficult to properly position and more difficult to extract once depleted. Further developments in biodegradable implants like Ozurdex $\AA$, as well as the development of alternative systems such as in-situ forming hydrogels, are likely to create less invasive intravitreal systems with similar capability to improve efficiency and reduce injection frequency. Subconjunctival and suprachoroidal injections and implants, as the youngest types of delivery systems, benefit from developments in other fields and are well-positioned to develop quickly once research locates optimal polymer formulations for both injectable solutions and implantable systems. For all of these methods, obtaining regulatory approval will be perhaps their most significant challenge. Many ocular drug delivery systems are listed in the FDA's drug databases, indicating that they were required to pass the FDA's drug approval process rather than obtaining device certification before reaching the open market. Despite this challenge in obtaining approval, dozens of polymer drug delivery systems are currently in clinical or preclinical trials for ocular applications, highlighting the immense potential many see for future growth in this field $(20,146,255)$. Overall, the future is bright for the use of polymers in ocular drug delivery systems, with a solid foundation of clinical technologies, dozens of registered clinical trials evaluating next-generation delivery systems for even higher efficiency, and further investigative research developing applications of new polymer science in ocular delivery.

\section{AUTHOR CONTRIBUTIONS}

MA and KS-R were responsible for study conception. MA, $\mathrm{RL}, \mathrm{EH}$, and KS-R: literature review, analysis, interpretation of results, and writing were conducted. MA was primarily responsible for drafting the manuscript. All authors reviewed the results and approved the final version of the manuscript.

\section{FUNDING}

We would like to acknowledge the Ohio State University College of Engineering, the Ohio Lions Eye Research Foundation, and the Research to Prevent Blindness Young Investigator Student Fellowship Award for Female Scholars in Vision Research for funding.

\section{ACKNOWLEDGMENTS}

We would like to acknowledge the past and present members of the Swindle-Reilly Lab for Biomimetic Polymeric Biomaterials for help and encouragement, particularly former lab members Pengfei Jiang, Nguyen Tram, and Courtney Maxwell for using polymers to advance work on ocular drug delivery. 


\section{REFERENCES}

1. WHO. World Report on Vision Executive Summary. World Health Organization. p. 1-12 (2019).

2. Eye Health Statistics-American Academy of Ophthalmology. Available online at: https://www.aao.org/newsroom/eye-health-statistics (2019)

3. BrightFocus Foundation. Sources for Macular Degeneration. Facts \& Figures. Available online at: https://www.brightfocus.org/sources-maculardegeneration-facts-figures (accessed Sep 13, 2021)

4. Rein DB, Wittenborn JS, Zhang X, Honeycutt AA, Lesesne SB, Saaddine J, et al. Forecasting age-related macular degeneration through the year 2050: the potential impact of new treatments. Arch. Ophthalmol. (2009) 127, 533-540. doi: 10.1001/archophthalmol.2009.58

5. Shahiwala A. Applications of polymers in ocular drug delivery. Appl Polym Drug Deliv. (2021) 355-92. doi: 10.1016/B978-0-12-819659-5.00013-6

6. Nartey A. The pathophysiology of cataract and major interventions to retarding its progression: a mini review. MedCrave. (2017) 6:13. doi: 10.15406/aovs.2017.06.00178

7. Weinreb RN, Aung T. The pathophysiology and treatment of glaucoma: a review. JAMA. (2014) 311:1901-11. doi: 10.1001/jama.2014.3192

8. Janson BJ, Alward WL, Kwon YH, Bettis DI, Fingert JH, Provencher LM. Glaucoma-associated corneal endothelial cell damage: a review. Surv Ophthalmol. (2018) 63:500-6. doi: 10.1016/j.survophthal.2017.11.002

9. Porta M. Diabetic retinopathy A clinical update. Diabetologia. (2002) 45:1617-34. doi: 10.1007/s00125-002-0990-7

10. Jager RD, Mieler WF. Age-related macular degeneration. $N$ Engl J Med. (2008) 358:2606-17. doi: 10.1056/NEJMra0801537

11. Wang W. Diabetic retinopathy : pathophysiology and treatments. Int J Mol Sci. (2018) 19:1-14. doi: 10.3390/ijms19061816

12. Fogli S, Mogavero S, Egan CG, Del Re M. Pathophysiology and pharmacological targets of VEGF in diabetic macular edema. Pharmacol Res. (2016) 103:149-57. doi: 10.1016/j.phrs.2015.11.003

13. Tram NK, McLean RM, Swindle-Reilly KE. Glutathione improves the antioxidant activity of vitamin $\mathrm{c}$ in human lens and retinal epithelial cells: implications for vitreous substitutes. Curr Eye Res. (2021) 46:47081. doi: 10.1080/02713683.2020.1809002

14. Kassa E, Ciulla TA, Hussain RM. Complement inhibition as a therapeutic strategy in retinal disorders. Expert Opin Biol Ther. (2019) 19:33542. doi: 10.1080/14712598.2019.1575358

15. Yu B, Li X-R, Zhang X-M. Mesenchymal stem cell-derived extracellular vesicles as a new therapeutic strategy for ocular diseases. World J. Stem Cells, 12:178-87. doi: 10.4252/wjsc.v12.i3.178

16. Karanfil FÇ, Turgut B. Update on presbyopia-correcting Drops Eur Ophthalmic Rev. 11:99. (2017). doi: 10.17925/EOR.2017.11.02.99

17. Vandenberghe LH. Novel adeno-associated viral vectors for retinal gene therapy. Gene Ther. (2012) 19:162-8. doi: 10.1038/gt.2011.151

18. Spinozzi E, Baldassarri C, Acquaticci L, Del Bello F, Grifantini M, Cappellacci L. Adenosine receptors as promising targets for the management of ocular diseases. Med Chem Res. (2021) 30:353-70. doi: 10.1007/s00044-021-02704-x

19. Gote V, Sikder S, Sicotte J. Ocular drug delivery: present innovations and future challenges. J Pharmacol Exp Ther. (2019) 370:602-24. doi: 10.1124/jpet.119.256933

20. Kang-Mieler JJ, Rudeen KM, Liu W. Advances in ocular drug delivery systems. Eye. (2020) 34:1371-9. doi: 10.1038/s41433-020-0809-0

21. Basile AS, Hutmacher MM, Kowalski KG, Gandelman KY.

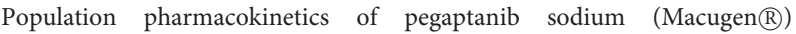
in patients with diabetic macular edema. Clin Ophthalmol. (2015) 9:323-35. doi: 10.2147/OPTH.S74050

22. Turecek PL, Bossard MJ, Schoetens F. PEGylation of biopharmaceuticals: a review of chemistry and nonclinical safety information of approved drugs. $J$ Pharm Sci. (2016) 105:460-75. doi: 10.1016/j.xphs.2015.11.015

23. Abdelkader H, Fathalla Z, Seyfoddin A, Farahani M,Thrimawithana T, Allahham A, et al. Polymeric long-acting drug delivery systems (LADDS) for treatment of chronic diseases: Inserts, patches, wafers, and implants. $A d v$ Drug Deliv Rev. (2021) 177:113957. doi: 10.1016/j.addr.2021.113957

24. Blizzard CD, Desai A, Driscoll A, Cheung M. Ocular pharmacokinetics of OTX-DED, a sustained-release intracanalicular insert delivering dexamethasone, in a canine model. IOVS. (2021) 62:1.
25. Hussain RM, Shaukat BA, Ciulla LM, Berrocal AM. Vascular endothelial growth factor antagonists: promising players in the treatment of neovascular age-related macular degeneration. Drug Des Devel Ther. (2021) 15:265365. doi: 10.2147/DDDT.S295223

26. Mah FSE. On gel formation time of adding topical ophthalmic medications to resure sealant, an in situ hydrogel. J Ocul Pharmacol Ther. (2016) 32:3969. doi: 10.1089/jop.2015.0112

27. Foroutan SM. The in vitro evaluation of polyethylene glycol esters of hydrocortisone 21-succinate as ocular prodrugs. Int J Pharm. (1999) 182:7992. doi: 10.1016/S0378-5173(99)00059-9

28. Eid HM, Elkomy MH, El Menshawe SF. Development, optimization, and in vitro/in vivo characterization of enhanced lipid nanoparticles for ocular delivery of ofloxacin: the influence of pegylation and chitosan coating. AAPS PharmSciTech. (2019) 20:1-14. doi: 10.1208/s12249-019-1371-6

29. Shatz W, Hass PE, Peer N, Paluch MT, Blanchette C, Han G. Identification and characterization of an octameric PEG-protein conjugate system for intravitreal long-acting delivery to the back of the eye. PLoS ONE. (2019) 14:1-20. doi: 10.1371/journal.pone.0218613

30. Lakhani P, Patil A, Wu K-W, Sweeney C, Tripathi S, Avula B. Optimization, stabilization, and characterization of amphotericin B loaded nanostructured lipid carriers for ocular drug delivery. Int J Pharm. (2019) 572:114. doi: 10.1016/j.ijpharm.2019.118771

31. Teodorescu M, Bercea M. Biomaterials of PVA and PVP in medical and pharmaceutical applications: Perspectives and challenges. Biotechnol Adv. (2019) 37:109-31. doi: 10.1016/j.biotechadv.2018.11.008

32. Kuno N. Biodegradable intraocular therapies for retinal disorders. Drugs Aging. (2010) 27:117-34. doi: 10.2165/11530970-000000000-00000

33. Arcinue CA, Ceró OM. A comparison between the fluocinolone acetonide (retisert) and dexamethasone (ozurdex) intravitreal implants in uveitis. $J$ Ocul Pharmacol Ther. (2012) 29:501-7. doi: 10.1089/jop.2012.0180

34. Habib MS. ILUVIEN@technology in the treatment of center-involving diabetic macular edema: a review of the literature. Ther Deliv. (2018) 9:54756. doi: 10.4155/tde-2018-0006

35. Schmit-Eilenberger VK. A novel intravitreal fluocinolone acetonide implant (Iluvien $($ ) ) in the treatment of patients with chronic diabetic macular edema that is insufficiently responsive to other medical treatment options: a case series. Clin Ophthalmol. (2015) 9:801-11. doi: 10.2147/OPTH.S79785

36. Paolini MS, Fenton OS, Bhattacharya C, Andresen JL. Polymers for extended-release administration. Biomed Microdevices 2019212 21. (2019) 1-24. doi: 10.1007/s10544-019-0386-9

37. Haghjou N, Soheilian M. Sustained release intraocular drug delivery devices for treatment of uveitis. J Ophthalmic Vis Res. (2011) 6:317-29.

38. García-Estrada P, García-Bon MA, López-Naranjo EJ, Basaldúa-Pérez DN, Santos A. Polymeric implants for the treatment of intraocular eye diseases: trends in biodegradable and non-biodegradable materials. Pharmaceutics. (2021) 13:1-20. doi: 10.3390/pharmaceutics13050701

39. Shin CS, Marcano DC, Park K. Application of hydrogel template strategy in ocular drug delivery. Methods Mol Biol. (2017) 1570:27985. doi: 10.1007/978-1-4939-6840-4_19

40. Makadia HK. Poly lactic-co-glycolic acid (PLGA) as biodegradable controlled drug delivery carrier. Polymers. (2011) 3:137797. doi: 10.3390/polym 3031377

41. Marin E, Briceño MI. Critical evaluation of biodegradable polymers used in nanodrugs. Int J Nanomed. (2013) 8:3071-91. doi: 10.2147/IJN.S47186

42. Farah S, Anderson DG. Physical and mechanical properties of PLA, and their functions in widespread applications-a comprehensive review. Adv Drug Deliv Rev. (2016) 107:367-92. doi: 10.1016/j.addr.2016.06.012

43. Kuppermann BD, Patel SS, Boyer DS, Augstin AJ, Freeman WR, Kerr KJ. Phase 2 study of the safety and efficacy of brimonidine drug delivery system (brimo dds) generation 1 in patients with geographic atrophy secondary to age-related macular degeneratiON. Retina. (2021) 41:144-55. doi: 10.1097/IAE.000000000000 2789

44. Baino F. Regulation of the ocular cell/tissue response by implantable biomaterials and drug delivery systems. Bioengineering. (2020) 7:131. doi: 10.3390/bioengineering7030065

45. Gentile P, Chiono V, Carmagnola I. An overview of poly(lacticco-glycolic) acid (PLGA)-based biomaterials for bone tissue 
engineering. Int J Mol Sci. (2014) 15:3640-59. doi: 10.3390/ijms15 033640

46. Cao Y, Samy KE, Bernards DA. Recent advances in intraocular sustained-release drug delivery devices. Drug Discovery Today. (2019) 24:1694-700. doi: 10.1016/j.drudis.2019. 05.031

47. Chan A, Leung L-S. Critical appraisal of the clinical utility of the dexamethasone intravitreal implant (Ozurdex $($ ) ) for the treatment of macular edema related to branch retinal vein occlusion or central retinal vein occlusion. Clin Ophthalmol. (2011) 5:1043-9. doi: 10.2147/OPTH.S1 3775

48. Shirley M. Bimatoprost implant: first approval. Drugs Aging. (2020) 37:45762. doi: 10.1007/s40266-020-00769-8

49. Liu W, Lee B-S, Mieler WF. Biodegradable microspherehydrogel ocular drug delivery system for controlled and extended release of bioactive aflibercept in vitro. Curr Eye Res. (2019) 44:264-74. doi: 10.1080/02713683.2018.153 3983

50. Liu W, Borrell MA, Venerus DC, Mieler WF. Characterization of biodegradable microsphere-hydrogel ocular drug delivery system for controlled and extended release of ranibizumab. Transl Vis Sci Technol. (2019) 8:1-13. doi: 10.1167/tvst.8.1.12

51. Osswald CR, Guthrie MJ, Avila A, Valio JA, Mieler WF, Kang-Mieler. In vivo efficacy of an injectable microsphere-hydrogel ocular drug delivery system. Curr Eye Res. (2017) 42:1293-301. doi: 10.1080/02713683.2017.1302590

52. Liu W, Tawakol AP, Rudeen KM, Mieler WF. Treatment efficacy and biocompatibility of a biodegradable aflibercept-loaded microspherehydrogel drug delivery system. Transl Vis Sci Technol. (2020) 9:114. doi: $10.1167 /$ tvst.9.11.13

53. Mondal D, Griffith M. Polycaprolactone-based biomaterials for tissue engineering and drug delivery: current scenario and challenges. Int $J$ Polym Mater Polym Biomater. (2016) 65:255-65. doi: 10.1080/00914037.2015.1103241

54. Malikmammadov E, Endogan Tanir T, Kiziltay A, Hasirci V. PCL and PCLbased materials in biomedical applications. J Biomater Sci Polym Ed. (2018) 29:863-93. doi: 10.1080/09205063.2017.1394711

55. Bernards DA, Bhisitkul RB, Wynn P, Steedman MR, Lee O-T, Wong F. Ocular biocompatibility and structural integrity of micro- and nanostructured poly(caprolactone) films. J. Ocul. Pharmacol. Ther. (2013). 29:24957. doi: 10.1089/jop.2012.0152

56. Samy KE, Cao Y, Kim J, Konichi S. Co-delivery of timolol and brimonidine with a polymer thin-film intraocular device. J Ocul Pharmacol Ther. (2019) 35:124-31. doi: 10.1089/jop.2018.0096

57. Hashemi Nasr F, Khoee S, Mehdi Dehghan M, Sadeghian Chaleshtori S. Preparation and evaluation of contact lenses embedded with polycaprolactone-based nanoparticles for ocular drug delivery. Biomolecules. (2015) 17:485-95. doi: 10.1021/acs.biomac.5b01387

58. Zhang Z, He Z, Liang R, Ma Y, Huang W, Jiang R. Fabrication of a micellar supramolecular hydrogel for ocular drug delivery. Biomacromolecules. (2016) 17:798-807. doi: 10.1021/acs.biomac.5b01526

59. Shahab MS, Rizwanullah M, Alshehri S. Optimization to development of chitosan decorated polycaprolactone nanoparticles for improved ocular delivery of dorzolamide: in vitro, ex vivo and toxicity assessments. Int J Biol Macromol. (2020) 163:2392-404. doi: 10.1016/j.ijbiomac.2020.09.185

60. Jiang P, Jacobs KM, Ohr MP. Chitosan-polycaprolactone core-shell microparticles for sustained delivery of bevacizumab. Mol Pharm. (2020) 17:2570-84. doi: 10.1021/acs.molpharmaceut.0c00260

61. Jiang P, Chaparro FJ, Cuddington CT, Palmer AF, Ohr MP, Lannutti JJ. Injectable biodegradable bi-layered capsule for sustained delivery of bevacizumab in treating wet age-related macular degeneration. J Control Release. (2020) 320:442-56. doi: 10.1016/j.jconrel.2020.01.036

62. Kim J, Judisch M, Mudumba S, Asada H, Aya-Shibuya E, Bhisitkul RB. Biocompatibility and pharmacokinetic analysis of an intracameral polycaprolactone drug delivery implant for glaucoma. Invest Ophthalmol Vis Sci. (2016) 57:4341-6. doi: 10.1167/iovs.16-19585

63. Souto EB, Dias-ferreira J, Ana L, Ettcheto M, Elena S. Advanced formulation approaches for ocular drug delivery : state-of-the-art and recent patents. Pharmaceutics. (2019) 11:1-29. doi: 10.3390/pharmaceutics11090460
64. Sovadinova I, Palmermo EF, Urban M, Mpiga P, Caputo GA. Activity and mechanism of antimicrobial peptide-mimetic amphiphilic polymethacrylate derivatives. Polymers. (2011) 3:1512-32. doi: 10.3390/polym3031512

65. Ali U, Juhanni Bt Abd Karim K, Aziah Buang NA. Review of the properties and applications of poly (methyl methacrylate) (PMMA). Polym Rev. (2015) 55:678-705. doi: 10.1080/15583724.2015.1031377

66. Fan X, Torres-Luna C, Azadi M, Domszy R, Hu N,Yang A, et al. Evaluation of commercial soft contact lenses for ocular drug delivery: a review. Acta Biomater. (2020) 115:60-74. doi: 10.1016/j.actbio.2020.08.025

67. Kiddee W, Trope GE, Sheng L, Beltran-Agullo L, Smith M, Strungaru MH, et al. (2013). Intraocular pressure monitoring post intravitreal steroids: a systematic review. Surv. Ophthalmol. 58, 291-310. doi: 10.1016/j.survophthal.2012.08.003

68. Ubani-Ukoma U, Gibson D, Schultz G, Silva BO. Evaluating the potential of drug eluting contact lenses for treatment of bacterial keratitis using an ex vivo corneal model. Int J Pharm. (2019) 565:499508. doi: 10.1016/j.ijpharm.2019.05.031

69. Pereira-da-Mota AF, Vivero-Lopez M, Topete A, Serro AP, Concheiro A, Alvarez-Lorenzo C. Atorvastatin-eluting contact lenses : effects of molecular imprinting and sterilization on drug loading and release. Pharmaceutics. (2021) 13:1-22. doi: 10.3390/pharmaceutics13050606

70. González-Chomón C, Silva M, Concheiro A. Biomimetic contact lenses eluting olopatadine for allergic conjunctivitis. Acta Biomater. (2016) 41:30211. doi: 10.1016/j.actbio.2016.05.032

71. Jung HJ. Temperature sensitive contact lenses for triggered ophthalmic drug delivery. Biomaterials. (2012) 33:2289300. doi: 10.1016/j.biomaterials.2011.10.076

72. Brannigan RP. Synthesis and evaluation of mucoadhesive acryloylquaternized PDMAEMA nanogels for ocular drug delivery. Colloids Surfaces B Biointerfaces. (2017) 155:538-43. doi: 10.1016/j.colsurfb.2017.04.050

73. Soni V, Pandey V, Tiwari R, Asati S, Tekade RK. Design and evaluation of ophthalmic delivery formulations. In: Basic Fundamentals of Drug Delivery. New york, NY: Academic Press (2019), p. 473-538.

74. Dung Nguyen D, Lai J-Y. Advancing the stimuli response of polymer-based drug delivery systems for ocular disease treatment. Polym Chem. (2020) 11:6988-7008. doi: 10.1039/D0PY00919A

75. Prasannan A, Tsai H-C, Chen Y-S. A thermally triggered in situ hydrogel from poly(acrylic acid-co-N-isopropylacrylamide) for controlled release of anti-glaucoma drugs. J Mater Chem B. (2014) 2:198897. doi: 10.1039/c3tb21360a

76. Prasannan A, Tsai HC. Formulation and evaluation of epinephrineloaded poly(acrylic acid-co-N-isopropylacrylamide) gel for sustained ophthalmic drug delivery. React Funct Polym. (2018) 124:40-7. doi: 10.1016/j.reactfunctpolym.2018.01.001

77. Mah F, Milner M, Yiu S, Donnenfeld E, Conway TM. PERSIST: Physician's Evaluation of Restasis $($ Satisfaction in Second Trial of topical cyclosporine ophthalmic emulsion $0.05 \%$ for dry eye: a retrospective review. Clin. Ophthalmol. (2012). 6:1971-6. doi: 10.2147/OPTH.S30261

78. Lancina MG III,Yang, H. Dendrimers for ocular drug delivery. Can J Chem. (2017) 95:897-902. doi: 10.1139/cjc-2017-0193

79. Yavuz B, Bozdag Pehlivan S. Dendrimeric systems and their applications in ocular drug delivery. Sci World J. (2013) 2013:1-13. doi: 10.1155/2013/732340

80. Madaan K, Kumar S, Poonia N, Lather V, Pandita D. Dendrimers in drug delivery and targeting: drug-dendrimer interactions and toxicity issues. $J$ Pharm Bioallied Sci. 6:139-50. doi: 10.4103/0975-7406.130965

81. Yavuz B, Pehlivan SB, Bolu BS, Sanyal RN, Vural I. DexamethasonePAMAM dendrimer conjugates for retinal delivery: preparation, characterization and in vivo evaluation. J Pharm Pharmacol. (2016) 68:1010-20. doi: 10.1111/jphp.12587

82. Iezzi R, Guru BR, Glybina IV, Mishra MJ, Kennedy A. Dendrimerbased targeted intravitreal therapy for sustained attenuation of neuroinflammation in retinal degeneration. Biomaterials. (2011) 33:979-88. doi: 10.1016/j.biomaterials.2011.10.010

83. Wang J, Williamson GS, Lancina MG III, Yang H. Mildly crosslinked dendrimer hydrogel prepared via aza-michael addition reaction for topical brimonidine delivery. J Biomed Nanotechnol. (2017) 13:108996. doi: $10.1166 /$ jbn. 2017.2436 
84. Aravamudhan A, Ramos DM, Nada AA. Natural polymers: polysaccharides and their derivatives for biomedical applications. Nat Synth Biomed Polym. (2014) 2014:67-89. doi: 10.1016/B978-0-12-396983-5.00004-1

85. Dutescu RM, Panfil C. Comparison of the effects of various lubricant eye drops on the in vitro rabbit corneal healing and toxicity. Exp Toxicol Pathol. (2017) 69:123-9. doi: 10.1016/j.etp.2016.12.002

86. Deng S, Li X, Yang W, He K, Ye X. Injectable in situ cross-linking hyaluronic acid/carboxymethyl cellulose based hydrogels for drug release. J Biomater Sci Polym. Ed. 29:1643-55. doi: 10.1080/09205063.2018.1481005

87. Yuan X, Marcano DC, Shin CS, Hua X, Isenhart LC, Pflugfelder SC. Ocular drug delivery nanowafer with enhanced therapeutic efficacy. ACS Nano. (2015) 9:1749-58. doi: 10.1021/nn506599f

88. Coursey TG, Henriksson JT, Marcano DC, Shin CS, Isenhart LC, Ahmed F. Dexamethasone nanowafer as an effective therapy for dry eye disease. $J$ Control Release. (2015) 213:168-74. doi: 10.1016/j.jconrel.2015.07.007

89. Tundisi LL, Mostaço GB, Carricondo PC. Hydroxypropyl methylcellulose: Physicochemical properties and ocular drug delivery formulations. Eur J Pharm Sci. (2021) 159:1-12. doi: 10.1016/j.ejps.2021.105736

90. Hu L, Sun Y. Advances in chitosan-based drug delivery vehicles. Nanoscale. (2013) 5:3103-11. doi: 10.1039/c3nr00338h

91. Cheng Y-H, Tsai T-H, Jhan Y-Y, Chiu AW-H, Tsai K-L, Chien C-S. Thermosensitive chitosan-based hydrogel as a topical ocular drug delivery system of latanoprost for glaucoma treatment. Carbohydr Polym. 144:3909. doi: 10.1016/j.carbpol.2016.02.080

92. Rong X, Yang J, Ji Y, Zhu X, Lu Y, Mo Z. Biocompatibility and safety of insulin-loaded chitosan nanoparticles/PLGA-PEG-PLGA hydrogel (ICNPH) delivered by subconjunctival injection in rats. J Drug Deliv Sci Technol. (2019) 49:556-62. doi: 10.1016/j.jddst.2018.12.032

93. Başaran E. Ocular application of chitosan. Expert Opin Drug Deliv. (2012) 9:701-12. doi: 10.1517/17425247.2012.681775

94. Arafa MG, Girgis GNS. Chitosan-coated PLGA nanoparticles for enhanced ocular anti-inflammatory efficacy of atorvastatin calcium. Int J Nanomed. (2020) 15:1335-47. doi: 10.2147/IJN.S237314

95. Chaharband F, Daftarian N, Kanavi MR, Varshochian R, Hajiramezanali M, Norouzi P. Trimethyl chitosan-hyaluronic acid nano-polyplexes for intravitreal VEGFR-2 siRNA delivery: formulation and in vivo efficacy evaluation. Nanomed Nanotechnol Biol Med. (2020) 26:1-12. doi: 10.1016/j.nano.2020.102181

96. Shi H, Wang Y, Bao Z, Lin D, Liu H, Yu A. Thermosensitive glycol chitosan-based hydrogel as a topical ocular drug delivery system for enhanced ocular bioavailability. Int J Pharm. (2019) 570:1-7. doi: 10.1016/j.ijpharm.2019.118688

97. Zhang X, Wei D, Xu Y, Zhu Q. Hyaluronic acid in ocular drug delivery. Carbohydr Polym. (2021) 264:1-24. doi: 10.1016/j.carbpol.2021.118006

98. Saranraj P. Hyaluronic acid production and its applications-a review. Int $J$ Pharm Biol Arch. (2013) 4:853-9.

99. Hemshekhar M, Thushara RM, Chandranayaka S, Shermen LS, Kemparaju K. Emerging roles of hyaluronic acid bioscaffolds in tissue engineering and regenerative medicine. Int J Biol Macromol. (2016) 86:917-28. doi: 10.1016/j.ijbiomac.2016.02.032

100. Liu Y, Wang R, Zarembinski T, Doty N, Jiang C, Regatieri C. The application of hyaluronic acid hydrogels to retinal progenitor cell transplantation. Tissue Eng Part A. (2013) 19:135-42. doi: 10.1089/ten.tea.2012.0209

101. Eom Y, Kim S, Huh J, Koh MY, Hwang JY, Kang B. Self-sealing hyaluronic acid-coated 30-gauge intravitreal injection needles for preventing vitreous and drug reflux through needle passage. Sci Rep. (2021) 11:110. doi: 10.1038/s41598-021-96561-8

102. Vasvani S, Kulkarni P. Hyaluronic acid: a review on its biology, aspects of drug delivery, route of administrations and a special emphasis on its approved marketed products and recent clinical studies. Int J Biol Macromol. (2020) 151:1012-29. doi: 10.1016/j.ijbiomac.2019.11.066

103. Jarvis B. Topical $3 \%$ diclofenac in $2.5 \%$ hyaluronic acid gel: a review of its use in patients with actinic keratoses. Am J Clin Dermatol. (2003) 4:20313. doi: 10.2165/00128071-200304030-00007

104. Diaz-Montes E. Sources, structures, and properties. Polysaccharides. (2021) 2:554-65. doi: 10.3390/polysaccharides 2030033
105. Kathuria A, Shamloo K, Jhanji V. Categorization of marketed artificial tear formulations based on their ingredients: a rational approach for their use. $J$ Clin Med. (2021) 10:1-11. doi: 10.3390/jcm10061289

106. Chaiyasan W, Srinivas SP. Crosslinked chitosan-dextran sulfate nanoparticle for improved topical ocular drug delivery. Mol Vis. (2015) 21:1224-34.

107. Delgado D, del Pozo-Rodríguez A, Solinís MÁ, Avilés-Triqueros M, Weber BH, Fernández E, et al. (2011). Dextran and protamine-based solid lipid nanoparticles as potential vectors for the treatment of X-linked juvenile retinoschisis. Hum Gene Ther. 23:345-55. doi: 10.1089/hum.2011.115

108. Mudgil D, Barak S. Guar gum: processing, properties and food applicationsa review. Human Gene Therapy. (2014) 23: 345-55.

109. Thombare N, Jha U, Mishra S. Guar gum as a promising starting material for diverse applications: a review. Int J Biol Macromol. (2016) 88:36172. doi: 10.1016/j.ijbiomac.2016.04.001

110. Labetoulle M, Schmickler S, Galarreta D, Böhringer D, Ogundele A, Guillon M, Baudouin C, et al. (2018). Efficacy and safety of dual-polymer hydroxypropyl guar- and hyaluronic acid-containing lubricant eyedrops for the management of dry-eye disease: a randomized double-masked clinical study. Clin Ophthalmol. 12:2499-508. doi: 10.2147/OPTH.S177176

111. Shi Q, Daisy ERAC, Yang G, Zhang J, Mickymaray S, Alfaiz FA. Multifeatured guar gum armed drug delivery system for the delivery of ofloxacin drug to treat ophthalmic dieases. Arab J Chem. (2021) 14:112. doi: 10.1016/j.arabjc.2021.103118

112. Cheng K-C, Demirci A. Pullulan: biosynthesis, production, and applications. Appl Microbiol Biotechnol. (2011) 92:29-44. doi: 10.1007/s00253-011-3477-y

113. Prajapati VD, Jani GK. Pullulan: an exopolysaccharide and its various applications. Carbohydr Polym. (2013) 95:5409. doi: 10.1016/j.carbpol.2013.02.082

114. Singh RS, Kaur N, Rana V. Recent insights on applications of pullulan in tissue engineering. Carbohydr Polym. (2016) 153:455-62. doi: 10.1016/j.carbpol.2016.07.118

115. Göttel B, Lucas H, Syrowatka F, Knolle W, Kuntsche J, Heinzelmann J. In situ gelling amphotericin B nanofibers: a new option for the treatment of keratomycosis. Front Bioeng Biotechnol. (2020) 8:384. doi: $10.3389 /$ fbioe.2020.600384

116. Pai G. Formulation and evaluation of extended release ocular inserts prepared from synthetic and natural biodegradable-biocompatible polymers. Res J Pharm Tech. (2014) 7:48-51.

117. Browne S, Zeugolis DI. Collagen: finding a solution for the source. Tissue Eng - Part A. (2013) 19:1491-4. doi: 10.1089/ten.tea.2012.0721

118. Khan R. Use of collagen as a biomaterial: an update. J Indian Soc Periodontol. (2013) 17:539-42. doi: 10.4103/0972-124X.118333

119. Wong FSY, Tsang KK, Chu AMW, Chan BP, Yao KM. Injectable cell-encapsulating composite alginate-collagen platform with inducible termination switch for safer ocular drug delivery. Biomaterials. (2019) 201:53-67. doi: 10.1016/j.biomaterials.2019.01.032

120. Zadeh MA, Khoder M, Al-Kinani AA, Younes HM. Retinal cell regeneration using tissue engineered polymeric scaffolds. Drug Discov Today. (2019) 24:1669-78. doi: 10.1016/j.drudis.2019.04.009

121. Belin MW, Lim L, Rajpal RK, Hafezi F, Gomes JAP. Corneal cross-linking: Current USA status report from the cornea society. Cornea. (2018) 37:121825. doi: 10.1097/ICO.0000000000001707

122. Gómez-Guillén MC, Giménez B, López-Caballero ME. Functional and bioactive properties of collagen and gelatin from alternative sources: a review. Food Hydrocoll. (2011) 25:1813-27. doi: 10.1016/j.foodhyd.2011.02.007

123. Rose JB, Pacelli S, El Haj AJ, Dua HS, Hopkinson A, White LJ. Gelatin-based materials in ocular tissue engineering. Materials. (2014) 7:3106. doi: 10.3390/ma7043106

124. Echave MC, Burgo LS, Pedraz JL. Gelatin as biomaterial for tissue engineering. Curr Pharm Design. 23:3567-84 (2017). doi: 10.2174/0929867324666170511123101

125. Song Y, Nagai N, Saijo S, Kaji H, Nishizawa M. In situ formation of injectable chitosan-gelatin hydrogels through double crosslinking for sustained intraocular drug delivery. Mater Sci Eng C Mater Biol Appl. (2018) 88:1-12. doi: 10.1016/j.msec.2018.02.022 
126. Tsai CH, Wang PY, Lin IC, Huang H, Liu GS. Ocular drug delivery: role of degradable polymeric nanocarriers for ophthalmic application. Int J Mol Sci. (2018) 19:2830. doi: 10.3390/ijms19092830

127. Chun YY, Yap ZL, Seet LF, Chan HH, Toh LZ, Chu SWL. Positivecharge tuned gelatin hydrogel-siSPARC injectable for siRNA anti-scarring therapy in post glaucoma filtration surgery. Sci Rep. (2021) 11:114. doi: 10.1038/s41598-020-80542-4

128. Batul R, Tamanna T, Khaliq A. Recent progress in the biomedical applications of polydopamine nanostructures. Biomater Sci. (2017) 5:120429. doi: 10.1039/C7BM00187H

129. Liu S, Zhao X, Tang J, Han Y. Drug-eluting hydrophilic coating modification of intraocular lens via facile dopamine self-polymerization for posterior capsular opacification prevention. ACS Biomater Sci Eng. (2021) 7:106573. doi: 10.1021/acsbiomaterials.0c01705

130. Jiang P, Choi A. Controlled release of anti-VEGF by redoxresponsive polydopamine nanoparticles. Nanoscale. (2020) 12:1-33. doi: 10.1039/D0NR03710A

131. Poinard B, Kamaluddin S, Tan AQQ, Neoh KG. Polydopamine coating enhances mucopenetration and cell uptake of nanoparticles. ACS Appl Mater Interfaces. (2019) 11:4777-89. doi: 10.1021/acsami.8b18107

132. Ciolacu DE, Nicu R. Cellulose-based hydrogels as sustained drug-delivery systems. Materials. (2020) 13:1-37. doi: 10.3390/ma13225270

133. Dubashynskaya N, Poshina D, Raik S, Urtti A. Polysaccharides in ocular drug delivery. Pharmaceutics. (2020) 12:130. doi: 10.3390/pharmaceutics 12010022

134. Desfrançois C, Auzély R. Lipid nanoparticles and their hydrogel composites for drug delivery: A review. Pharmaceuticals. (2018) 11:1-24. doi: 10.3390/ph11040118

135. Sung YK. Recent advances in polymeric drug delivery systems. Biomater Res. (2020) 24:1-12. doi: 10.1186/s40824-020-00190-7

136. Tiwari S. Modified hyaluronic acid based materials for biomedical applications. Int J Biol Macromol. (2019) 121:55671. doi: 10.1016/j.ijbiomac.2018.10.049

137. Tripodo G, Trapani A, Torre ML, Giammona G, Trapani G. Hyaluronic acid and its derivatives in drug delivery and imaging: recent advances and challenges. Eur J Pharm Biopharm. (2015) 97:400-16. doi: 10.1016/j.ejpb.2015.03.032

138. Verma D. Recent advances in guar gum based drug delivery systems and their administrative routes. Int J Biol Macromol. (2021) 181:65371. doi: 10.1016/j.ijbiomac.2021.03.087

139. Göttel B, Souza de Silva C, de Oliveira CS, Syrowatka F, Fiorentzis M, Viestenz A, et al. Electrospun nanofibers-a promising solid in-situ gelling alternative for ocular drug delivery. Eur J Pharm Biopharm. 146:12532. doi: 10.1016/j.ejpb.2019.11.012

140. Balasso A, Subrizi A, Salmaso S, Mastrotto F, Garofalo M, Tang M. Screening of chemical linkers for development of pullulan bioconjugates for intravitreal ocular applications. Eur J Pharm Sci. (2021) 161:105785. doi: 10.1016/j.ejps.2021.105785

141. Dionísio M, Braz L, Corvo M, Lourenço JP, Grenha A, Costa AM. Charged pullulan derivatives for the development of nanocarriers by polyelectrolyte complexation. Int J Biol Macromol. (2016) 86:129-38. doi: 10.1016/j.ijbiomac.2016.01.054

142. Liu S, Jones L. Nanomaterials for ocular drug delivery. Macromol Biosci. (2012) 12:608-20. doi: 10.1002/mabi.201100419

143. Maulvi FA, Soni TG. A review on therapeutic contact lenses for ocular drug delivery. Drug Deliv. (2016) 23:301726. doi: 10.3109/10717544.2016.1138342

144. Halasz K, Kelly SJ, Iqbal MT, Pathak Y, Sutariya V. Micro/nanoparticle delivery systems for ocular diseases. Assay Drug Dev Technol. (2019) 17:15266. doi: 10.1089/adt.2018.911

145. Esteban-Peréz S, Bravo-Osuna I, Andrés-Guerrero V, Molina-Martínez IT. Trojan microparticles potential for ophthalmic drug delivery. Curr Med Chem. (2020) 27:570-82. doi: 10.2174/0929867326666190905150331

146. Gorantla S, Rapalli VK, Waghule T, Singh PP, Dubey SK, Saha RN. Nanocarriers for ocular drug delivery: current status and translational opportunity. RSC Adv. (2020) 10:27835-55. doi: 10.1039/D0RA04971A

147. Bravo-Osuna I, Andrés-Guerrero V, Abal PP, Molina-Martínez IT. Pharmaceutical microscale and nanoscale approaches for efficient treatment of ocular diseases. Drug Deliv Transl Res. (2016) 6:686-707. doi: 10.1007/s13346-016-0336-5

148. Qamar Z, Qizilbash FF, Iqubal MK, Ali A, Narang JK, Ali J. Nano-based drug delivery system: recent strategies for the treatment of ocular disease and future perspective. Recent Pat Drug Deliv Formul. (2019) 13:24654. doi: 10.2174/1872211314666191224115211

149. Momin MM. Nanoformulations and highlights of clinical studies for ocular drug delivery systems: an overview. Crit Rev Ther Drug Carrier Syst. (2021) 38:79-107. doi: 10.1615/CritRevTherDrugCarrierSyst.2021035767

150. Li H, Palamoor M. Poly(ortho ester) nanoparticles targeted for chronic intraocular diseases: ocular safety and localization after intravitreal injection. Nanotoxicology. (2016) 10:1152-9. doi: 10.1080/17435390.2016.11 81808

151. Fu S, Yang G, Wang J, Wang X, Cheng X, Zha Q. pH-sensitive poly(ortho ester urethanes) copolymers with controlled degradation kinetic: synthesis, characterization, and in vitro evaluation as drug carriers. Eur Polym J. (2017) 95:275-88. doi: 10.1016/j.eurpolymj.2017.08.023

152. Ug urlu N, Aşik MD, Çakmak HB, Tuncer S, Turk M, Çagil N, et al. Transscleral delivery of bevacizumab-loaded chitosan nanoparticles. J Biomed Nanotechnol. (2019) 15, 830-838. doi: 10.1166/jbn.2019.2716

153. Lu Y, Zhou N, Huang X, Cheng J, Li F, Wei R. Effect of intravitreal injection of bevacizumab-chitosan nanoparticles on retina of diabetic rats. Int J Ophthalmol. (2014) 7:1-7.

154. Dionísio M, Cordeiro C, Remuñán-López C, Seijo B, Rosa C. Pullulan-based nanoparticles as carriers for transmucosal protein delivery. Eur J Pharm Sci. (2013) 50:102-13. doi: 10.1016/j.ejps.2013.04.018

155. Garhwal R, Shady SF, Ellis EJ, Ellis JY, Leahy CD. McCarthy, SP, et al. Sustained ocular delivery of ciprofloxacin using nanospheres and conventional contact lens materials. Investig Ophthalmol Vis Sci. (2012) 53:1341-52. doi: 10.1167/iovs.11-8215

156. Mahor A, Prajapati SK, Verma A, Gupta R, Iyer AK. Moxifloxacin loaded gelatin nanoparticles for ocular delivery: formulation and in-vitro, in-vivo evaluation. J Colloid Interface Sci. (2016) 483:132-8. doi: 10.1016/j.jcis.2016.08.018

157. Grimaudo MA, Pescina S, Padula C, Santi P, Concheiro A, Alvarez-Lorenzo C. Topical application of polymeric nanomicelles in ophthalmology: a review on research efforts for the noninvasive delivery of ocular therapeutics. Expert Opinion on Drug Deliv. (2019) 16:397-413. doi: 10.1080/17425247.2019.159 7848

158. Mandal A, Bisht R, Rupenthal ID. Polymeric micelles for ocular drug delivery: From structural frameworks to recent preclinical studies. J Control Release. (2017) 248:96-116. doi: 10.1016/j.jconrel.2017.0 1.012

159. Sun F, Zheng Z, Lan J, Li X, Li M, Song K. New micelle myricetin formulation for ocular delivery: improved stability, solubility, and ocular anti-inflammatory treatment. Drug Deliv. (2019) 26:575-85. doi: $10.1080 / 10717544.2019 .162$ 2608

160. Devi S, Saini V, Kumar M, Bhatt S, Gupta S. A novel approach of drug localization through development of polymeric micellar system containing azelastine $\mathrm{HCl}$ for ocular delivery. Pharm Nanotechnol. (2019) 7:31427. doi: 10.2174/2211738507666190726162000

161. Grimaudo MA, Amato G, Carbone C, Diaz-Rodriguez P, Musumeci T, Concheiro A. Micelle-nanogel platform for ferulic acid ocular delivery. Int J Pharm. (2020) 576:118986. doi: 10.1016/j.ijpharm.2019.118986

162. Maulvi FA, Parmar RJ, Desai AR, Desai DM, Shukla MR, Ranch KM. Tailored gatifloxacin Pluronic $($ F-68-loaded contact lens: addressing the issue of transmittance and swelling. Int J Pharm. (2020) 581:119279. doi: 10.1016/j.ijpharm.2020.11 9279

163. Durgun ME, Kahraman E, Güngör S. Optimization and characterization of aqueous micellar formulations for ocular delivery of an antifungal drug, posaconazole. Curr Pharm Des. (2020) 26:1543-55. doi: 10.2174/1381612826666200313172207

164. Safwat MA, Mansour HF, Hussein AK, Abdelwahab S. Polymeric micelles for the ocular delivery of triamcinolone acetonide: preparation and in vivo evaluation in a rabbit ocular inflammatory model. Drug Deliv. (2020) 27:1115-24. doi: 10.1080/10717544.2020.1797241 
165. Liu D, Wu Q, Chen W, Lin H, Zhu Y, Liu Y. A novel FK506 loaded nanomicelles consisting of amino-terminated poly(ethylene glycol)-blockpoly(D,L)-lactic acid and hydroxypropyl methylcellulose for ocular drug delivery. Int J Pharm. (2019) 562:1-10. doi: 10.1016/j.ijpharm.2019.03.022

166. Zamboulis A, Nanaki S, Michailidou G, Koumentakou I, Lazaridou M, Ainali NM. Chitosan and its derivatives for ocular delivery formulations: recent advances and developments. Polymers. (2020) 12:1-67. doi: 10.3390/polym12071519

167. Xu X, Sun L, Zhou L, Cheng Y. Functional chitosan oligosaccharide nanomicelles for topical ocular drug delivery of dexamethasone. Carbhohydr Polym. (2020) 227:115356. doi: 10.1016/j.carbpol.2019. 115356

168. Alami-Milani M, Zakeri-Milani P, Valizadeh H, Salehi R, Salatin S, Naderinia A. Novel pentablock copolymers as thermosensitive selfassembling micelles for ocular drug delivery. Adv Pharm Bull. (2017) 7:1120. doi: 10.15171/apb.2017.003

169. Nasir NAA, Alyautdin RN, Agarwal R, Nukolova N, Cheknonin V. Ocular tissue distribution of topically applied PEGylated and non-PEGylated liposomes. Adv Mater Res. (2014) 832:18. doi: 10.4028/www.scientific.net/AMR.832.1

170. Danion A, Arsenault I. Antibacterial activity of contact lenses bearing surface-immobilized layers of intact liposomes loaded with levofloxacin. J Pharm Sci. (2007) 96:2350-63. doi: 10.1002/jps. 20871

171. Swindle-Reilly KE, Maxwell CJ, Soltisz AM, Choi A, Rich W. Injectable alginate hydrogels for traumatic optic neuropathy. Investig Ophthalmol Vis Sci. (2021) 62:2682.

172. Reilly MA, Swindle-Reilly KE. Hydrogels for intraocular lenses and other ophthalmic prostheses. Biomed Hydrogels. 2011:11848. doi: 10.1533/9780857091383.2.118

173. Xie L, Yue W, Ibrahim K. A long-acting curcumin nanoparticle/in situ hydrogel composite for the treatment of uveal melanoma. Pharmaceutics. (2021) 13:1335. doi: 10.3390/pharmaceutics13091335

174. Zhang J, Muirhead B, Dodd M, Liu L, Xu F, Mangiacotte N. An injectable hydrogel prepared using a PEG/Vitamin E copolymer facilitating aqueous-driven gelation. Biomacromolecules. (2016) 17:3648-58. doi: 10.1021/acs.biomac.6b01148

175. Tram NK, Jiang P, Torres-Flores TC, Jacobs KM, Chandler HL. A hydrogel vitreous substitute that releases antioxidant. Macromol Biosci. (2020) 20:1900305. doi: 10.1002/mabi.201900305

176. Tan DWN, Lim SG, Wong TT. Sustained antibiotic-eluting intra-ocular lenses: a new approach. PLoS ONE. (2016) 11:1-14. doi: 10.1371/journal.pone.0163857

177. Anumolu SNS, DeSantis AS, Menjoge AR, Hahn RA, Beloni JA, Gordon $\mathrm{MK}$, et al. Doxycycline loaded poly(ethylene glycol) hydrogels for healing vesicant-induced ocular wounds. Biomaterials. (2010) 31:96474. doi: 10.1016/j.biomaterials.2009.10.010

178. El-Feky YA, Fares AR, Zayed G, El-Telbany RFA, Ahmed KA. Repurposing of nifedipine loaded in situ ophthalmic gel as a novel approach for glaucoma treatment. Biomed Pharmacother. (2021) 142:112008. doi: 10.1016/j.biopha.2021.112008

179. Fedorchak MV, Conner IP, Schuman JS, Cugini A. Long term glaucoma drug delivery using a topically retained gel/microsphere eye drop. Sci Rep. (2017) 7:1-11. doi: 10.1038/s41598-017-09379-8

180. Kelley RA, Ghaffari A, Wang Y, Choi S, Taylor JR, Hartman RR. Manufacturing of dexamethasone-poly(d,l-Lactide-co-Glycolide) implants using hot-melt extrusion: within- and between-batch product performance comparisons. J Ocul Pharmacol Therap. (2020) 36:290-7. doi: 10.1089/jop.2019.0074

181. Kiss S. Sustained-release corticosteroid delivery systems. Retin Today. (2010) 2010:44-46.

182. Polat HK, Pehlivan SB, Özkul C, Çalamak S, Öztürk N, Aytekin E. Development of besifloxacin $\mathrm{HCl}$ loaded nanofibrous ocular inserts for the treatment of bacterial keratitis: In vitro, ex vivo and in vivo evaluation. Int J Pharm. (2020) 585:119552. doi: 10.1016/j.ijpharm.2020.119552

183. Singla J, Bajaj T, Goyal AK. Development of nanofibrous ocular insert for retinal delivery of fluocinolone acetonide. Curr Eye Res. (2019) 44:54150. doi: 10.1080/02713683.2018.1563196
184. Mirzaeei S, Berenjian K. Preparation of the potential ocular inserts by electrospinning method to achieve the prolong release profile of triamcinolone acetonide. Adv Pharm Bull. (2018) 8:21. doi: 10.15171/apb.2018.003

185. Grimaudo MA, Concheiro A. Crosslinked hyaluronan electrospun nanofibers for ferulic acid ocular delivery. Pharmaceutics. (2020) 12:274. doi: 10.3390/pharmaceutics12030274

186. Yin C, Liu Y, Qi X, Guo C. Kaempferol incorporated bovine serum albumin fibrous films for ocular drug delivery. Macromol Biosci. (2021) 21:2100269. doi: 10.1002/mabi.202100269

187. Perry JL, Herlihy KP, Napier ME, DeSimone JM. PRINT: a novel platform toward shape and size specific nanoparticle theranostics. Acc Chem Res. (2011) 44:990-8. doi: 10.1021/ar2000315

188. DeSimone JM. Co-opting Moore's law: therapeutics, vaccines and interfacially active particles manufactured via PRINT®. J Control Release. (2016) 240:541-3. doi: 10.1016/j.jconrel.2016.07.019

189. Aerie Pharmaceuticals, Inc. Drug Delivery. Available online at: https:// aeriepharma.com/rd/pipeline/drug-delivery/ (accessed Sep 29, 2021).

190. Meng T, Kulkarni V, Simmers R, Brar V. Therapeutic implications of nanomedicine for ocular drug delivery. Drug Discov Today. (2019) 24:152438. doi: 10.1016/j.drudis.2019.05.006

191. Narayana S, Ahmed MG, Gowda BHJ, Shetty PK, Nasrine A, Thriveni M. Recent advances in ocular drug delivery systems and targeting VEGF receptors for management of ocular angiogenesis: a comprehensive review. Futur J Pharm Sci. (2021) 7:1-21. doi: 10.1186/s43094-021-00331-2

192. Glendenning A, Crews K, Sturdivant J, deLong MA, Kopczynski C, Lin C. Sustained release, biodegradable PEA implants for intravitreal delivery of the ROCK/PKC inhibitor AR-13503. Invest Ophthalmol Vis Sci. (2018) 59:5672.

193. Study Assessing. AR-13503 Implant in Subjects With nAMD or DME - Full Text View - ClinicalTrials.gov. Available online at: https://clinicaltrials.gov/ ct2/show/NCT03835884 (accessed Sep 30, 2021).

194. ClinicalTrials.gov. Safety and Efficacy of ENV515 Travoprost Extended Release (XR) in Patients With Bilateral Ocular Hypertension or Primary Open Angle Glaucoma-Full Text View. Available online at: https://clinicaltrials. gov/ct2/show/study/NCT02371746 (accessed Sep 30, 2021).

195. Kesav NP, Young CEC, Ertel MK, Seibold LK. Sustained-release drug delivery systems for the treatment of glaucoma. Int J Ophthalmol. (2021) 14:14859. doi: 10.18240/ijo.2021.01.21

196. Mansberger SL, Conley J, Verhoeven RS, Blackwell K, Depenbusch M, Knox T. Interim analysis of low dose ENV515 travoprost XR with 11 month duration followed by dose escalation and 28 day efficacy evaluation of high dose ENV515. Invest Ophthalmol Vis Sci. (2017) 58:2110.

197. Rafiei F, Tabesh H. Sustained subconjunctival drug delivery systems: current trends and future perspectives. Int Ophthalmol. (2020) 40:2385401. doi: 10.1007/s10792-020-01391-8

198. Jumelle C, Gholizadeh S, Annabi N. Advances and limitations of drug delivery systems formulated as eye drops. J Control Release. (2020) 321:122. doi: 10.1016/j.jconrel.2020.01.057

199. Gooch N, Molokhia SA, Condie R, Burr RM, Archer B, Ambati BK. Ocular drug delivery for glaucoma management. Pharmaceutics. (2012) 4:197-211.

200. Awwad S, Ahmed AHAM, Sharma G, Heng JS, Khaw PT, Brocchini S. Principles of pharmacology in the eye. Br J Pharmacol. (2017) 174:420523. doi: 10.1111/bph.14024

201. Gaballa SA, Kompella UB, Elgarhy O, Alqahtani AM, Pierscionek B, Alany RG. Corticosteroids in ophthalmology: drug delivery innovations, pharmacology, clinical applications, and future perspectives. Drug Deliv Transl Res. (2021) 11:866-93. doi: 10.1007/s13346-020-00843-z

202. Janagam $\mathrm{DR}, \mathrm{Wu} \mathrm{L}$. Nanoparticles for drug delivery to the anterior segment of the eye. Adv Drug Deliv Rev. (2017) 122:31-64. doi: 10.1016/j.addr.2017.04.001

203. Cabrera FJ, Wang DC, Reddy K, Acharya G. Challenges and opportunities for drug delivery to the posterior of the eye. Drug Discov Today. (2019) 24:1679-84. doi: 10.1016/j.drudis.2019.05.035

204. Johannsdottir S, Jansook P, Stefansson E, Kristinsdottir IM, Fulop Z, Asgrimsdottir GM. Topical drug delivery to the posterior segment of the eye: Dexamethasone concentrations in various eye tissues after topical administration for up to 15 days to rabbits. J Drug Deliv Sci Technol. (2018) 45:449-54. doi: 10.1016/j.jddst.2018.04.007 
205. Mangiacotte N, Prosperi-Porta G, Liu L, Dodd M. Mucoadhesive nanoparticles for drug delivery to the anterior eye. Nanomaterials. (2020) 10:1-16. doi: 10.3390/nano10071400

206. Dave RS, Goostrey TC, Ziolkowska M, Czerny-Holownia S, Hoare T. Ocular drug delivery to the anterior segment using nanocarriers: A mucoadhesive/mucopenetrative perspective. J Control Release. (2021) 336:71-88. doi: 10.1016/j.jconrel.2021.06.011

207. Kim YC, Shin MD, Hackett SF, Hsueh HT, Silva RLE, Date A. Gelling hypotonic polymer solution for extended topical drug delivery to the eye. Nat Biomed Eng. (2020) 4:1053-62. doi: 10.1038/s41551-020-00606-8

208. Voss K, Falke K, Bernsdorf A, Grabow N, Kastner C, Sternberg K. Development of a novel injectable drug delivery system for subconjunctival glaucoma treatment. J Control Release. (2015) 214:1-11. doi: 10.1016/j.jconrel.2015.06.035

209. Zhou C, Singh A, Qian G, Wolkow N, Dohlman CH, Vavvas DG. Microporous drug delivery system for sustained anti-vegf delivery to the eye. Transl Vis Sci Technol. (2020) 9:5. doi: 10.1167/tvst.9.8.5

210. Cheng Y-H, Hung KH, Tsai T-H, Lee C-J, Ku R-Y, Chiu AW-H. Sustained delivery of latanoprost by thermosensitive chitosan-gelatin-based hydrogel for controlling ocular hypertension. Acta Biomater. (2014) 10:4360-6. doi: 10.1016/j.actbio.2014.05.031

211. Li J, Tian S, Tao Q, Zhao Y, Gui R, Yang F. Montmorillonite/chitosan nanoparticles as a novel controlled-release topical ophthalmic delivery system for the treatment of glaucoma. Int J Nanomedicine. (2018) 13:397587. doi: $10.2147 /$ IJN.S162306

212. Tahara K, Karasawa K, Onodera R. Feasibility of drug delivery to the eye's posterior segment by topical instillation of PLGA nanoparticles. Asian J Pharm Sci. (2017) 12:394-9. doi: 10.1016/j.ajps.2017.03.002

213. Kompella UB, Kadam RS. Recent advances in ophthalmic drug delivery. Ther Deliv. (2010) 1:435-56. doi: 10.4155/tde.10.40

214. Kim YC, Hsueh HT, Shin MD, Berlinicke CA, Han H, Anders NM, et al. hypotonic gel-forming eye drop provides enhanced intraocular delivery of a kinase inhibitor with melanin-binding properties for sustained protection of retinal ganglion cells. Drug Deliv Transl Res. (2021). doi: 10.1007/s13346-021-00987-6

215. Fedorchak MV, Conner IP, Medina CA, Wingard JB, Schuman JS. 28-day intraocular pressure reduction with a single dose of brimonidine tartrate-loaded microspheres. Exp Eye Res. (2014) 125:210-6. doi: 10.1016/j.exer.2014.06.013

216. Jessen BA, Shiue MHI, Kaur H, Miller P, Leedle R, Guo H. Safety assessment of subconjunctivally implanted devices containing latanoprost in dutch-belted rabbits. J Ocul Pharmacol Ther. (2013) 29:574-85. doi: 10.1089/jop.2012.0190

217. Lee RMH, Bouremel Y, Eames I, Brocchini S. The implications of an $\mathrm{Ab}$ Interno versus $\mathrm{Ab}$ externo surgical approach on outflow resistance of a subconjunctival drainage device for intraocular pressure control. Transl Vis Sci Technol. (2019) 8:58. doi: 10.1167/tvst.8.3.58

218. Rai UDJP, Young SA, Thrimawithana TR, Abdelkader H, Alani AWG, Pierscionek B. The suprachoroidal pathway: a new drug delivery route to the back of the eye. Drug Discov Today. (2015) 20:491-5. doi: 10.1016/j.drudis.2014.10.010

219. Olsen TW, Feng Z, Wabner K, Conston SR, Sierra DH, Folden DV. Cannulation of the suprachoroidal space: a novel drug delivery methodology to the posterior segment. Am J Ophthalmol. (2006) 142:77787. doi: 10.1016/j.ajo.2006.05.045

220. Gilger BC, Abarca EM, Salmon JH. Treatment of acute posterior uveitis in a porcine model by injection of triamcinolone acetonide into the suprachoroidal space using microneedles. Investig Ophthalmol Vis Sci. (2013) 54:2483-92. doi: 10.1167/iovs.13-11747

221. Einmahl S, Savoldelli M, D'Hermies F, Tabatabay C, Gurny R. Evaluation of a novel biomaterial in the suprachoroidal space of the rabbit eye. Investig Ophthalmol Vis Sci. (2002) 43:1533-9.

222. Chiang B, Venugopal N, Grossniklaus HE, Jung JH, Edelhauser HF. Thickness and closure kinetics of the suprachoroidal space following microneedle injection of liquid formulations. Investig Ophthalmol Vis Sci. (2017) 58:555-64. doi: 10.1167/iovs.16-20377

223. Chiang B, Venugopal N, Edelhauser HF. Distribution of particles, small molecules and polymeric formulation excipients in the suprachoroidal space after microneedle injection. Exp Eye Res. (2016) 153:101-9. doi: 10.1016/j.exer.2016.10.011

224. Moga KA, Bickford LR, Geil RD, Dunn SS, Pandya AA, Wang Y. Rapidly-dissolvable microneedle patches via a highly scalable and reproducible soft lithography approach. Adv Mater. (2013) 25:50606. doi: 10.1002/adma.201300526

225. Jung JH, Desit P. Targeted drug delivery in the suprachoroidal space by swollen hydrogel pushing. Investig Ophthalmol Vis Sci. (2018) 59:206979. doi: 10.1167/iovs.17-23758

226. Rauck BM, Friberg TR, Medina Mendez CA, Park D, Shah V, Bilonick RA. Biocompatible reverse thermal gel sustains the release of intravitreal bevacizumab in vivo. Investig Ophthalmol Vis Sci. (2014) 55:46976. doi: 10.1167/iovs.13-13120

227. Huang X. Intravitreal nanoparticles for retinal delivery. Drug Discov Today. (2019) 24:1510-23. doi: 10.1016/j.drudis.2019.05.005

228. Balachandra A, Chan EC, Paul JP, Ng S, Chrysostomou, Ngo S, et al. A biocompatible reverse thermoresponsive polymer for ocular drug delivery. Drug Deliv. (2019) 26:343-53. doi: 10.1080/10717544.2019.1587042

229. Prosperi-Porta G, Muirhead B. Tunable release of ophthalmic therapeutics from injectable, resorbable, thermoresponsive copolymer scaffolds. J Biomed Mater Res - Part B Appl Biomater. (2017) 105:53-62. doi: 10.1002/jbm.b.33501

230. Sheshala R, Hong GC, Yee WP, Meka VS. In situ forming phase-inversion implants for sustained ocular delivery of triamcinolone acetonide. Drug Deliv Transl Res. (2019) 9:534-42. doi: 10.1007/s13346-018-0491-y

231. Home-Re-Vana. Vision In The Future. (2021). Available online at: https:// www.revanatx.com/ (accessed Sep 08, 2021).

232. Khanani AM, Callanan D, Dreyer R, Chen S, Howard JG, Hopkins JJ. Endof-study results for the ladder phase 2 trial of the port delivery system with ranibizumab for neovascular age-related macular degeneration. Ophthalmol Retina. (2021) 5:775-87. doi: 10.1016/j.oret.2020.11.004

233. Genentech, Inc. Multicenter Phase II Randomized, Active TreatmentControlled Study of the Efficacy and Safety of the Ranibizumab Port Delivery System for Sustained Delivery of Ranibizumab in Patients With Subfoveal Neovascular Age-Related Macular Degeneration. Genentech, Inc. (2018).

234. DailyMed. TRIESCENCE-Triamcinolone Acetonide Injection, Suspension. (2020). Available online at: https://dailymed.nlm.nih.gov/dailymed/ drugInfo.cfm?setid=3f045347-3e5e-4bbd-90f8-6c3100985ca5 (accessed Sep 31, 2021).

235. ILUVIEN 190 Micrograms Intravitreal Implant in Applicator. (2019). Available online at: https://iluvien.com/wp-content/uploads/2015/03/ Prescribing-Information.pdf(accessed Sep 14, 2021).

236. Ozurdex. (2021). Available online at: https://www.ozurdex.com/ (accessed Sep 17, 2021).

237. Tso SC. The Chemistry Review for A/NDA 21-737 (2005). doi: 10.2476/asjaa.54.21

238. NDA 208742/S001 (2019). Available online at: https://www.accessdata.fda. gov/drugsatfda_docs/label/2019/208742s001lbl.pdf (accessed Sep 28, 2021).

239. Chaudhari P, Ghate VM. Next-generation contact lenses: towards bioresponsive drug delivery and smart technologies in ocular therapeutics. Eur J Pharm Biopharm. (2021) 161:80-99. doi: 10.1016/j.ejpb.2021.02.007

240. Safarzadeh M, Azizzadeh P. Comparación de la eficacia clínica de los colirios con conservantes y los colirios con contenido de hidroxipropil metilcelulosa-dextran sin conservantes. J Optom. (2017) 10:258-64. doi: 10.1016/j.optom.2016.11.002

241. Mydriasert 0. 28. $\mathrm{mg} / 5.4 \mathrm{mg}$ Ophthalmic Insert-Summary of Product Characteristics $(S m P C)-(e m c)$. Available online at: https://www.medicines. org.uk/emc/product/4672/smpc\#gref (accessed Sep 28, 2021).

242. Tobradex Eye Drops-Summary of Product Characteristics (SmPC)(emc). Available online at: https://www.medicines.org.uk/emc/product/ 1324/smpc\#gref (accessed Sep 28, 2021).

243. Chaudhary A, Salinas L, Guidotti J, Mermoud A. XEN Gel Implant: a new surgical approach in glaucoma. Expert Rev Med Devices. (2018) 15:4759. doi: 10.1080/17434440.2018.1419060

244. O'Rourke MJO. History, Status, and Trends for the Future. Cataract \& Refractive Surgery Today. (2019). Available online at: https://crstodayeurope. com/articles/2019-june/ophthalmic-drug-delivery-history-status-andtrends-for-the-future/ (accessed Sep 09, 2021). 
245. Our Pipeline-Kodiak Sciences. (2021). Available online at: https://kodiak. com/our-pipeline/ (accessed Sep 29, 2021).

246. Aerie Pharmaceuticals, Inc. AR-1105 Implant. (2020). Available online at: https://aeriepharma.com/rd/retinal-disease/ar-1105/ (accessed Sep 29, 2021).

247. Wagh V, Inamdar B. Polymers used in ocular dosage form and drug delivery systems. Asian J Pharm. (2008) 2:12-7. doi: 10.4103/0973-8398. 41558

248. Peng Y, Ang M, Foo S, Lee WS, Ma Z, Venkatraman SS. Biocompatibility and biodegradation studies of subconjunctival implants in rabbit eyes. PLoS ONE. (2011) 6:22507. doi: 10.1371/journal.pone.0022507

249. Mora-Pereira M, Abarca EM, Duran S, Ravis W, McMullen RJ Jr, Fischer, $\mathrm{BM}$, et al. Sustained-release voriconazole-thermogel for subconjunctival injection in horses: ocular toxicity and in-vivo studies. BMC Vet Res. (2020) 16:1-14. doi: 10.1186/s12917-020-02331-5

250. Paula JS, Ribeiro VR, Chahud F, Cannellini R, Monteiro TC,Gomes EC, et al. Bevacizumab-loaded polyurethane subconjunctival implants: effects on experimental glaucoma filtration surgery. J Ocul Pharmacol Ther. (2013) 29:566-573. doi: 10.1089/jop.2012.0136

251. Bausch Health And Clearside Biomedical Announce US, FDA. Filing Acceptance For XIPERETM (Triamcinolone Acetonide Suprachoroidal Injectable Suspension) (2021).

252. Kammer JA. Suprachoroidal devices in glaucoma surgery. Middle East Afr J Ophthalmol. (2015) 22:45-52. doi: 10.4103/0974-9233.148348

253. Campochiaro PA, Marcus DM, Awh CC, Regillo C, Adamis AP, Bantseev $\mathrm{V}$. The port delivery system with ranibizumab for neovascular age-related macular degeneration: results from the randomized phase 2 ladder clinical trial. Ophthalmology. (2019) 126:1141-54. doi: 10.1016/j.ophtha.2019.03.036
254. 20 OptimEyes-Micelle Technology. Available online at: https://www. 2020optimeyes.ca/micelle-technology (accessed Sep 28, 2021).

255. Kim HM. Ocular drug delivery to the retina: current innovations and future perspectives. Pharmaceutics. (2021) 13:1-32. doi: 10.3390/pharmaceutics13010108

Conflict of Interest: KS-R consults for and has equity interest in Vitranu, Inc., who has licensed ocular drug delivery technologies from her lab. KS-R has patent applications for ocular drug delivery technologies.

The remaining authors declare that the research was conducted in the absence of any commercial or financial relationships that could be construed as a potential conflict of interest.

Publisher's Note: All claims expressed in this article are solely those of the authors and do not necessarily represent those of their affiliated organizations, or those of the publisher, the editors and the reviewers. Any product that may be evaluated in this article, or claim that may be made by its manufacturer, is not guaranteed or endorsed by the publisher.

Copyright (C) 2022 Allyn, Luo, Hellwarth and Swindle-Reilly. This is an open-access article distributed under the terms of the Creative Commons Attribution License (CC $B Y)$. The use, distribution or reproduction in other forums is permitted, provided the original author(s) and the copyright owner(s) are credited and that the original publication in this journal is cited, in accordance with accepted academic practice. No use, distribution or reproduction is permitted which does not comply with these terms. 